INVEST Working Papers 17/2020

\title{
Inter-cohort wealth development in Finland, 1987-2016
}

Esa Karonen

Mikko Niemelä

28.8.2020 
The Inequalities, Interventions, and New Welfare State (INVEST) aims at increasing wellbeing of Finnish society during childhood, youth and early adulthood and preventing psychosocial risks compromising such development through innovative interventions. Based on cutting-edge research on the conditions and mechanisms involved at different periods of development, INVEST will evaluate and develop various universal and targeted interventions to improve the efficiency of the current welfare state institutions at critical points of the early life course. INVEST aims at providing a new model for the welfare states that is more equal, better targeted to problem groups, more anticipatory as well as economically and socially sustainable. INVEST is a Flagship project of the Academy of Finland. 


\title{
Inter-cohort wealth development in Finland, 1987-2016
}

\author{
Authors: \\ Esa Karonen ${ }^{1} *$ and Mikko Niemelä ${ }^{1}$ \\ ${ }^{1}$ University of Turku, Faculty of Social Sciences, Sociology, 20014, Turku, Finland \\ *Corresponding author, email: eokaro@utu.fi
}

\begin{abstract}
:
This article examines inter-cohort wealth development in Finland during the period 19872016. As previous research has stated that annual variation has increased over time, we aim to improve previous research by focusing on gross, net, and financial wealth gaps between cohorts. The opening of the Finnish financial markets and the introduction of new types of investment instruments since the late 1980s created entirely new circumstances for business and financial markets. We utilise the time series of the Official Statistics of Finland's (OFS) Household Assets. We use the marginal effects method with a generalised linear model (GLM), and interaction terms. The results show that inter-cohort wealth inequality in gross- and net wealth has not increased over time, and all differences are attributed to within-year variations. As a new finding, financial wealth shows variations among three distinct investment groups, and higher investment interest can be associated with decreasing initial investment ages among younger cohorts. It seems that younger cohorts embraced new financial instruments much more in early age than did their older counterparts. Overall, the results show that financial deregulation considerably increased investment in financial assets among all cohort groups.
\end{abstract}

\section{Keywords:}

wealth distribution, cohorts, life course, financial wealth, gross wealth, net wealth 


\section{Introduction}

Since Thomas Piketty's (2013) seminal book on economic inequality in Europe and the United States, there has been rising interest and debate on the role of the economy and wealth inequality. Piketty's central argument is that when the rate of growth is low, wealth tends to accumulate more quickly from returns to capital than from labour, and tends to accumulate more among the top $10 \%$ and $1 \%$, increasing inequality measures. His thesis has sparked a major global debate about capitalism, inequality, and taxation policy (for critiques, see Acemoglu \& Robinson 2015, Soskice 2014). However, much of the empirical research on economic inequality has focussed on income distribution, and thus, detailed analyses of the evolution of wealth inequality are still side-lined. As a whole, wealth has been studied from the viewpoint of age (Díaz-Giménez, Quadrini, \& Ríos-Rull, 1997; Hurst, Luoh, Stafford, \& Gale, 1998; Wolff, 1998) and generation (Hansen, 2014); and social origins (Charles \& Hurst, 2003; Conley \& Glauber, 2019.; Pfeffer \& Killewald, 2018), parental and family wealth (Hall \& Crowder, 2011; Hällsten \& Pfeffer, 2017; Pfeffer \& Killewald, 2018; Prix \& Pfeffer, 2017), and education (Conley, 2001; Conley \& Ryvicker, 2005; Gittleman \& Wolff, 2004; Hall \& Crowder, 2011; Keister, 2003, 2004; McKernan, Ratcliffe, Simms, \& Zhang, 2014).

Seeking to contribute to the literature on wealth distribution and inter-cohort inequalities, this article examines inter-cohort wealth development in Finland during the period 1987-2016. This study aims to improve upon previous studies in multiple ways. We approach our research questions from the perspective of cohorts to contribute to previous studies. Cohort studies have usually been conducted on data that do not have a satisfactory yield in statistical years. Second, this study focuses on the periodic range, which covers the transition to open financial markets, and thus offers the opportunity to observe multiple points of economic fluctuation over time and their impact on wealth. 
Previous research describes five main components of wealth distribution in Western nations. First, there is a consensus that wealth is more highly concentrated than income (Davies \& Shorrocks, 2000). Second, the highest concentration of wealth seems to concentrate in those groups that have a higher level of income. Hence, wealth is distributed more unequally than income, which is also a less-studied indicator of social balance. Third, most of the household wealth in European countries is concentrated in housing assets than in financial instruments, though previous studies point to within- and between-country differences in wealth (Sierminska \& Takhtamanova, 2007). Fourth, significant wealth effect differences are found across age groups (Sierminska \& Takhtamanova, 2007). Thus, from the life cycle perspective, the pattern of the wealth accumulation of households conforms to the predictions of the life-cycle model, as a large share of wealth accumulation is done by the young and the middle-aged.

Fifth, prior research shows that there are significant generational differences in economic measures such as income, consumption, and wealth (Berloffa \& Villa, 2010; Jappelli, 1999; Lim \& Zeng, 2016). However, the relationship between wealth and cohorts, that is, the generational pattern of wealth development, is far less studied than the effects of age and period on wealth dynamics. Existing research shows that there are significant generational differences in cohort profiles that draw attention to the negative role of period profiles, such as economic shocks, which reinforce the role of financial wealth in the Baby Boom generation (Lim \& Zeng, 2016). Overall, between cohorts, average wealth increases with age.

The Finnish case acts as a marvellous example for changing the institutional wealth distribution framework. The opening of the Finnish financial markets and the introduction of new types of investment instruments since the late 1980s and early the 1990s, combined with the ICT boom in the latter part of the 1990s, created entirely new circumstances for business 
and financial markets. The increase in income inequality during the latter part of the 1990s was one of the fastest in the OECD hemisphere (OECD, 2011). At the same time, the role of financial assets became more dominant in the wealth structure, especially among the highest deciles. Institutional factors concerning financial deregulation in the late 1980s, together with dual-taxation reform in 1993, were responsible for the shift from earnings to capital income. In turn, this meant a diminishing redistributive role of the welfare state, and rising net wealth inequality (Blomgren et al., 2014).

The Finnish evidence suggests that there is a clear period effect in wealth inequality. The unique Finnish case, combined with the long time-series data utilised in this study, provides an ideal context in which to focus on inter-cohort wealth distribution to chart the effects of the new financial instruments. However, to fully understand the evolution of wealth inequality, one needs to take account of age, time, and generation (Green, 2010; Hutchison, 2010; Kahneman \& Riis, 2005; Mayer, 2009). In terms of age, the accumulation of wealth usually takes time, and the peak of wealth is usually reached rather late in one's life. Have older cohorts who have more equity available adopted new financial instruments? Do younger cohorts, born in the 1970s or later, utilise these opportunities more readily, as they have always been available to them? In other words, do certain cohorts tend to invest in the more diverse opportunities that have become available?

\section{Background, previous research, and the framework of analysis}

Economic theories on wealth accumulation usually lean towards the life-cycle hypothesis, which predicts that at the individual level, wealth increases up to retirement, and declines smoothly thereafter. One key aspect of the life-cycle model is that growth takes place across generations, but not over the lifetime of a single individual (Modigliani, 1986; Deaton, 1999). This implies that an increase in productivity growth redistributes resources from older to 
younger generations, inducing an increase in the aggregate-saving rate, and thus in wealth accumulation. Research on wealth distribution over cohorts suggests testable identification assumptions. The aim of the model is to make predictions based on the wealth profiles on age (Díaz-Giménez et al., 1997; Hurst et al., 1998; Wolff, 1998), as well as predictions about the cohort effects (Charles \& Hurst, 2003; Conley \& Glauber, n.d.; Mulligan, 1997; Pfeffer \& Killewald, 2018). The life-cycle model, however, entails problematic assumptions, such as retirees using all their accumulated assets during retirement. However, there is evidence that wealth accumulation is driven by precautionary motives at the beginning of the life cycle, whereas savings for retirement purposes become significant only closer to retirement (Cagetti, 2003). To complicate matters, the nonparametric wealth-age profiles support the existence of an early and middle adulthood life-cycle 'squeeze', suggesting that the traditional hump-shaped wealth-age profile does not fully capture the dynamics of the economic life-cycle (Iacoviello \& Pavan, 2013).

Instead of the life-cycle model, this study emphasises a life course framework. Here, the central focus is to map out if a certain generation carries unique characteristics that it acquires through shared socialisation and periodical changes, as seen in how different birth cohorts grow up in a similar historical period (Mannheim, 1928). In an economic context, this can be described as inequality because some cohorts may have different life-course events due to their specific economic situation. Thus, an economic up- or downturn can play an enormous role in how a given generation is able to establish itself during changing market situations, which is connected to wealth accumulation (Frankenberg, Smith, \& Thomas, 2003; Lovenheim \& Reynolds, 2013). For example, cohorts who became adults during economic booms are more likely to profit from favourable market situations or from the other financial instruments available. Conversely, cohorts affected by an economic downturn may be more risk-averse and have less wealth-building options available during the life course (Attanasio 
et al., 1999; Cagetti, 2003; Karonen \& Niemelä, n.d.; Lusardi et al., 2017; Malmendier \& Nagel, 2011).

We can therefore assume that the three dimensions of age, economic period, and year of birth play a role in both economic outcomes and economic behaviour. Periodical changes in wealth trajectories and distribution can be tracked through outward stimuli, for example, through macroeconomic shocks (Mayer, 2000, 2009). They indicate how sociopolitical reactions against economic downturns have changed the wealth dynamics between generations. These cohort changes are key to creating a more solid picture of how different mechanisms of inequalities across generations are constructed. There are sensitive life course periods connected to age and different economic situations.

\section{Previous research}

Previous research on comparative age variations indicates that, on average, wealth increases over the life course until the individual reaches the 60-year mark (Díaz-Giménez et al., 1997; Hurst et al., 1998; Wolff, 1998). This illustrates the cumulative nature of wealth over the life course. Furthermore, wealth's role as an indicator of socioeconomic advantage may change over the course of life. For example, if net worth is lower for young adults than who have invested in higher education, their current wealth position is likely not the best indicator of their long-term financial prospects (Conley, 2001; Conley \& Ryvicker, 2005). This is consistent with the relatively lower correlation between income and wealth for young adults. In young adulthood, investments in higher education may lead to high income before student loan debt is paid off. Education is still associated with greater wealth and more rapid wealth accumulation (Conley, 2001; Conley \& Ryvicker, 2005; Keister, 2003; Yamokoski \& Keister, 2006). This may be compared to previous results from the United States, where education differences on wealth are high, with the median college-educated household having approximately $\$ 375,000$ in wealth at age 65 . In contrast, high school dropouts at the same age 
had accumulated only $\$ 125,000$, with most of that in the form of housing wealth (Lusardi et al., 2017).

From the cohort perspective, previous estimates of intergenerational wealth mobility suggest that the correlation of wealth across generations in the United States is roughly 0.3 to 0.4 , similar to the intergenerational persistence in other measures of socioeconomic attainment (Charles \& Hurst, 2003; Conley \& Glauber, 2008; Mulligan, 1997; Pfeffer \& Killewald, 2018). Similarly, when tracking wealth mobility in Europe, strong intergenerational wealth persistence at the top of the distribution also characterises more egalitarian Norway (Hansen, 2014). In addition, cohort differences connect to economic periods, as higher inflation rates constitute a broader economic factor influencing wealth inequality by advantaging young, middle-class households' wealth positions at the expense of older and richer households (Doepke \& Schneider, 2006).

Periodical results show that macroeconomic fluctuations, political institutions, and institutional structures also shape wealth levels and inequality. Cross-country differences in the distribution of wealth diverge from those based on income. There are both similarities and differences in patterns of wealth-holding across countries. Housing accounts for a large part of net worth in all countries. The share of financial assets is also important, although there is considerable variation across countries (Jäntti, Sierminska, \& Smeeding, 2008; Skopek, Buchholz, \& Blossfeld, 2014). Overall, high levels of wealth inequality are found in Sweden and Denmark, two countries widely considered to be highly egalitarian societies; conversely, southern European countries, where income inequality is relatively high, exhibit comparatively low levels of wealth inequality (Skopek et al., 2014). More specific institutional and economic determinants of wealth levels and inequality are yet to be identified (Semyonov \& Lewin-Epstein, 2013). 


\section{Finnish context and framework of analysis}

Overall, wealth is unevenly distributed among the Finnish population, as evidence suggests is common in more egalitarian societies (Jäntti et al., 2008; Skopek et al., 2014). Previous research shows that the wealthiest of the tenth decile and the households of the elderly are wealthier, and young people are weighed down by indebtedness, which could be connected to a temporary periodical fluctuation in a certain cohort (see, e.g., Conley \& Ryvicker, 2005). The characteristics of birth cohorts, such as risk-taking, inheritance motives, or consumption habits, may also differ, and may affect the propensity to save and to gain wealth. On the other hand, changes in the structure of households can also affect the age profile of wealth (Cribb, 2019; Crossley et al., 2016). Thus, based on the above, our first research hypothesis is the following: long-term wealth differences have increased among cohorts.

As age is a key factor in explaining wealth distribution, we can assume that wealth is accumulated eventually because of savings, inheritances, and other capital transfers. In line with comparative research, average Finnish net worth typically increases with age, but begins to decline with older age groups. Previous research shows that in the 2016 data, the average net worth was highest in the age group 65-74 years, which is slightly higher than in other countries (Díaz-Giménez et al., 1997; Hurst et al., 1998; Wolff, 1998). Compared to the 1994-2009 surveys, the highest net worth was in the 55-64 age group, and in the late 1980s in the 45-54 age group. Then again, this is dictated by measuring methods. By contrast, assets before debt reduction have been more evenly distributed over age and were, on average, almost equal in the 45-54 and 65-74 age groups (Törmälehto, Matala, and Junes, 2018). The factors behind the change are economic events and structural changes and, of course, the fact that age groups have different birth cohorts. Considering these facts, our 
second research hypothesis is as follows: as annual variation increases over time, gross, net, and financial wealth gaps between cohorts have increased.

The net worth of Finnish households has more than doubled over the last twenty years. In 2016, Finnish households had an average gross wealth of $€ 303,600$ and a net wealth of $€ 136,600$ per household, while in 1987 gross wealth was $€ 63,686$ and a net wealth $€ 51,800$. Figure 1 illustrates how wealth variance has changed over time. First, between period 19871994, there is no significant increase in yearly wealth variation, which indicates that wealth during this period is distributed in a similar fashion without any increase among households (see also Törmälehto, 2016; Törmälehto, 2018). After this period, we observe a significant increase in wealth inequality, after the economic shock of the 1990s, which has continued in the 2000s. Lorenz curves show that internal variation increases within each measurement year.
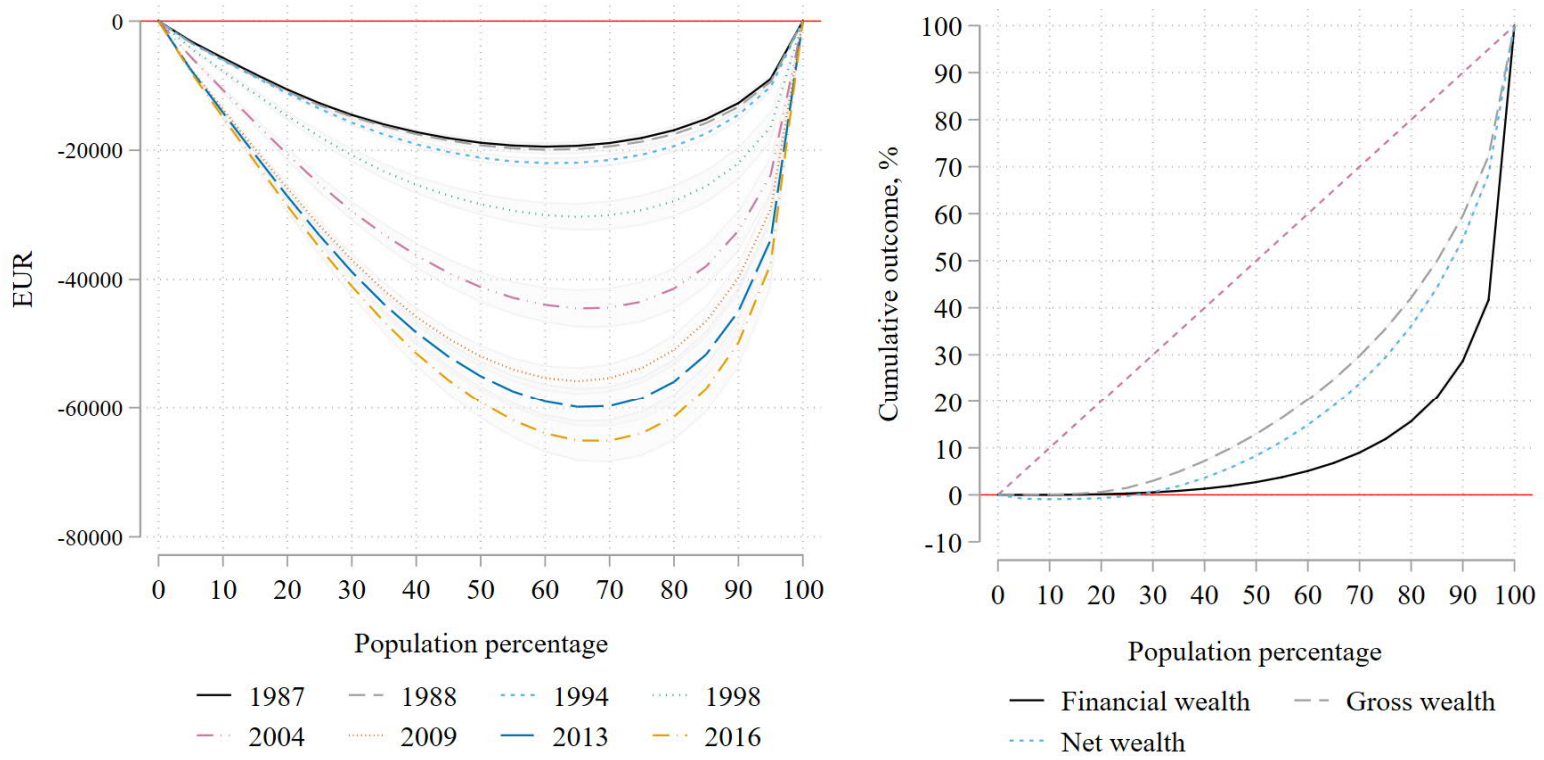

Figure 1. Data-level absolute Lorenz curves on net wealth by measurement years in inflation-adjusted and equivalised euros in 2016 rates (left panel), and cumulative Lorenz curves on financial assets and gross and net wealth (right panel).

Figure 1 reveals that most of the financial wealth has a significantly higher concentration in small population groups. In addition, when we order population by income, 
most of the general and financial wealth is distributed among the highest $20 \%$ income group. The wealthiest $5 \%$ of households own $71 \%$ of all financial wealth (Säylä, 2012). Previous research shows that financial assets consist of wealthy retirees, who hold a considerable part of the financial wealth. Working-age people have a wealth of gross financial assets, but they also have a great deal of debt. Surprisingly, those with smaller pensions also have relatively higher amounts of financial assets (Kauko, 2016). Previous Finnish research shows that between 1994 and 2009, younger birth cohorts tended to be more prosperous than their predecessors were at the same age (Törmälehto, 2016). Combined with findings that show a positive role of financial wealth for both Baby Boomers and Generation X (Lim \& Zeng, 2016), as financial wealth has a U-shaped profile, we can assume that both extremes of the cohort spectrum have a high interest in financial assets. As younger cohorts are relatively more prosperous than the older generations and have financial assets available from an earlier age, we assume that they might have a higher preference to utilise these instruments. Based on this, our third and final research hypothesis concerns financial wealth: after opening financial markets, investment in financial wealth has increased more in younger cohorts who had earlier access to financial instruments, and have relatively more resources than older cohorts did at the same age.

\section{Aims, data, and variables}

In this study, we aim to measure inter-cohort wealth development in Finland from 19872016. We do this by studying cohort differences over time in gross, net, and financial wealth to capture a larger scope of wealth variations, including the effect of financial deregulation on household finances.

We utilise the time series of the Official Statistics of Finland's (OFS) Household Assets dataset. The wealth survey describes household assets, such as their total amount, structure, 
and distribution among different population groups. The survey also consists of other matters that have a bearing on the financial position of households, such as income and debts. The survey also includes data on debt and income. Data on wealth are obtained using various estimation methods, where the data sources are register data. Overall, one usual downside of wealth data is the measurement range (Killewalad et al., 2017). Our dataset offers an improvement for previous studies, as our dataset spans from 1987 to 2016. It is worth noting certain data collection changes in the Household Assets dataset. In 1987, 1988, 1994, and 1998, the data were collected as an interview study in connection with the data collection of income distribution statistics. The 2004 survey (the Housing and Wealth Survey) was a separate survey. The 2009 survey is based on a sample of income statistics, but with a revised methodology without separate data collection. Income distribution statistics for the sample households are linked to, for example, housing, shareholdings, and vehicle registration information. Not all asset types are available for statistical use registry information, which has necessitated the use of different estimation methods. Due to the revised method, comparability varies from asset to asset. Despite the changed method, the time series is comparable with respect to the main items of wealth.

For the purposes of this study, the analyses were limited to the population aged $20-80$. The rationale for excluding 18- and 19-year-olds is the requirement for conscription in the Finnish Defense Force (6-12 months) and the requirement for civilian service (12 months). For example, conscription usually occupies approximately 14,000 people annually. In addition, population weights are used to account for demographic structure in the population.

In addition, cohort variables were consistent with previous studies and figure readability while maintaining an appropriate level of estimation resolution. Cohorts were divided into 10-year intervals from 1930-1990. The formed variables were constricted by the age factor of 20- to 80-year-olds to restrict the range to the active working population and retirement age. 


\section{Measurement of wealth}

The descriptive statistics of the dependent and independent variables are shown in Table 1. As dependent variables, we measure annual household gross, net, and financial wealth. The gross wealth variable consists of several components: value of the dwellings and other dwellings; other dwellings; transportation; forests; value of arable land; net worth of business activities; net worth of a group; total deposits; listed shares; other shares; investment funds; bonds; participation certificates; individual pension insurance; and savings and investment assets. Household net wealth is given by the difference between the gross wealth of a household and its liabilities. Logic choosing gross and net wealth as indicators is simple: indebtedness is a concept closely tied to wealth, and household indebtedness is usually included in the definition of wealth. Finally, we also use financial wealth as a dependent variable to measure changes in investment rates after financial market deregulation. The variable consists of deposits quoted, shares, other shares, fund shares, pension insurance, and savings. Household wealth concepts are not top-coded (see OSF 2015).

This study uses the equivalence scale, which is a variant of the Oxford scale. The equivalence scale is constructed with the formula $\mathrm{m}=1+\mathrm{a}(\mathrm{A}-1)+\mathrm{bL}$, where $\mathrm{A}$ is the number of adults and $\mathrm{L}$ is the number of children in the household. The value of parameter a is 0.5 , and $\mathrm{b}$ is 0.3 . This paper uses the Oxford scale, in which the reference person of the household is 14 years old or older.

\section{Independent variables}

We use three main independent variables. Dummy coding for the categorised variables can be found in Table 1. Education is associated with greater wealth and more rapid wealth accumulation and net income (Conley, 2001b; Conley \& Ryvicker, 2004; Keister, 2003a,b, 2004; Yamokoski \& Keister, 2006). In addition, it is possible that education is a proxy for 
prior income streams not captured by the current income measure, given the previously described challenges of modelling cumulative wealth with current income. Alternatively, education may affect wealth through the positive association between education and ownership of assets with higher risks and returns (Hanna, Wang, \& Yuh, 2010; Kim, Hanna, Chatterjee, \& Lindamood, 2012). Education is also a measure of information that individuals hold, as they make more nuanced economic decisions or are more aware of the possibilities of financial instruments (Cole et al., 2008; Douglas \& Isherwood, 1996; Hastings et al., 2013). Main economic activity represents the actual position in the job market during the measurement period, which can deviate from education. For example, the main type of economic activity is more impactful on household income at the cohort and period level than on education (Karonen \& Niemelä, 2018). Thus, the resources available and the stability of the individual's labour market also play a role in the willingness to invest or save. We also control for measurement years, which are associated with macroeconomic circumstances, political institutions, and institutional structures, which shape wealth levels and inequality. In addition, we use cohorts as the main object of research, as they hold the key to differences during time-sensitive events and the connection to economic environment and opportunities. 


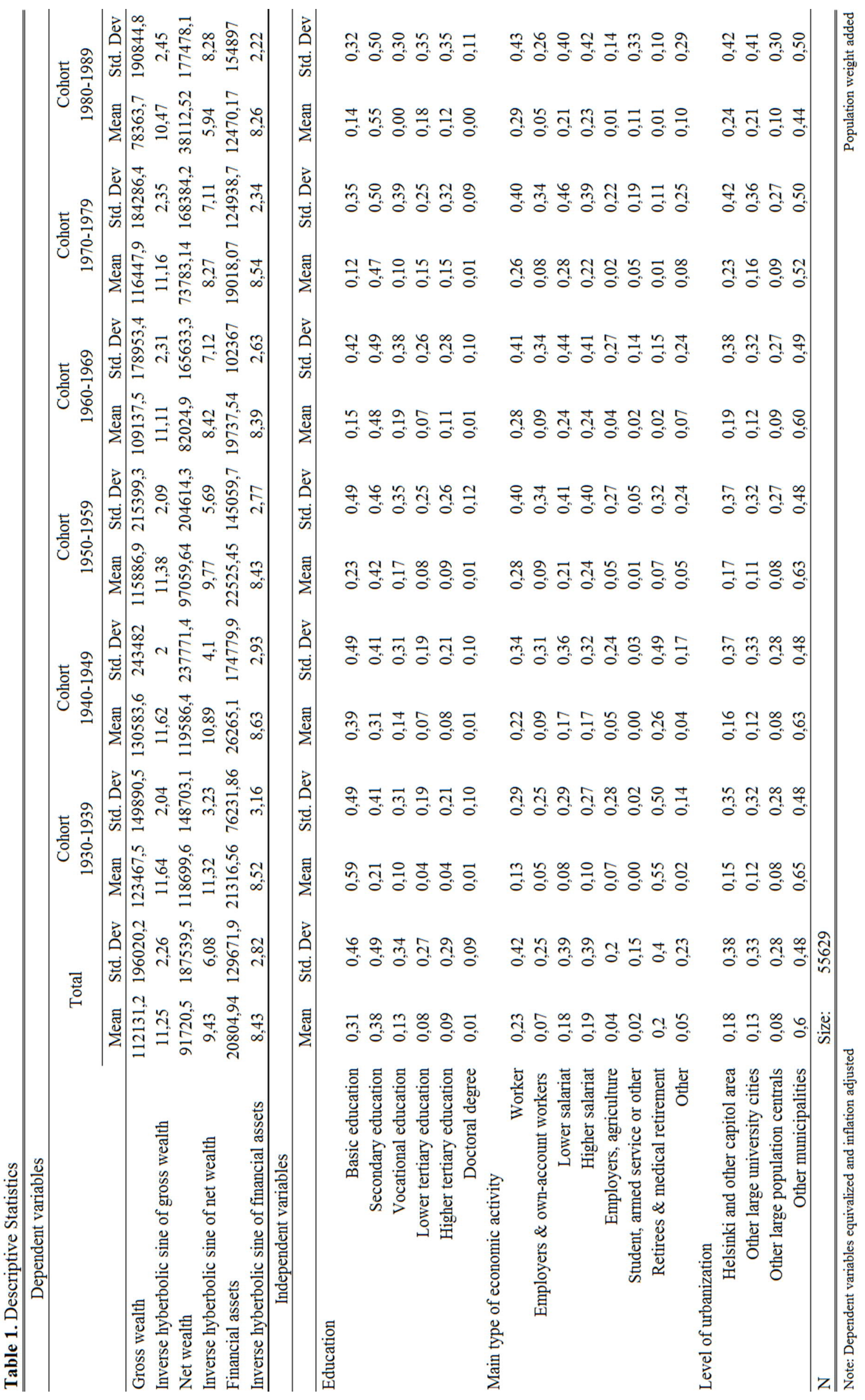




\section{Method}

The analysis will be confined to comparing differences in wealth effects between age groups during the observation period. For this purpose, regressions with interaction terms of the cohort dummies and income and wealth components are performed for the whole sample and the subsample of control variables.

Using wealth as the dependent variable raises many questions as wealth distribution is highly skewed. The usual solution is a logarithm transformation, which assumes that changes in independent variables have multiplicative effects on net worth, whereas the untransformed specification assumes additive effects. This is an inadvisable solution (Killewald et al., 2017), as recoding negative values to a small positive value obscures relative net debt values and creates an outlier mass point at the low end of the log net worth distribution (Friedline et al., 2015). Our solution is to use inverse hyperbolic sine (IHS) transformation, which can incorporate zero and negative values, generating a function that is approximately linear close to zero and approximately logarithmic for large values (Friedline, Masa, \& Chowa, 2015; Pence, 2006). Our dependent variables are the inverse hyperbolic sine of all listed wealth concepts, which are equivalized and adjusted for inflation. For ease of interpretation of the results, we transform IHS coefficient measures back into euro values by using the inverse function $\frac{1}{2}(\exp (\beta x)+\exp (-\beta x))($ see Pence, 2006).

We use the marginal effects method with a generalised linear model (GLM), and interaction terms on birth cohort $\mathrm{c}$ and period $\mathrm{t}$ dummy variables. We use a generalised linear model instead of OLS because the inverse hyperbolic sine is a non-linear transformation and OLS is a linear model. The problem is that when modelling, if the dependent variable is $y$, $\overline{\operatorname{asinh}(y)}$ and its inverse function $\frac{1}{2}(\exp (\beta)+\exp (-\beta))$ does not equal the correct mean transformation for the dependent variable's estimate, $\beta$ but with the GLM log link function, 
we model the transformed mean of $y$ rather than the mean of transformed $y$, which solves the problem (for more discussion, see Feng et al., 2014). An explanatory variable in the model is wealth, and the control variables are education level, main type of economic activity, and level of urbanisation. In the first model, we use the interaction term of period and cohorts, and in the second model cohort and age groups.

In addition, as a robustness check, we ran all the analyses as multilevel models with statistical years as a level, but we observed that intraclass correlation was extremely low. This test result validated the use of marginal effects instead of a multilevel model.

\section{Results}

Figure 2 shows descriptive statistics on median gross and net wealth by age, period, and cohort. Here we can observe several general things from the dataset connected to the life course hypothesis.
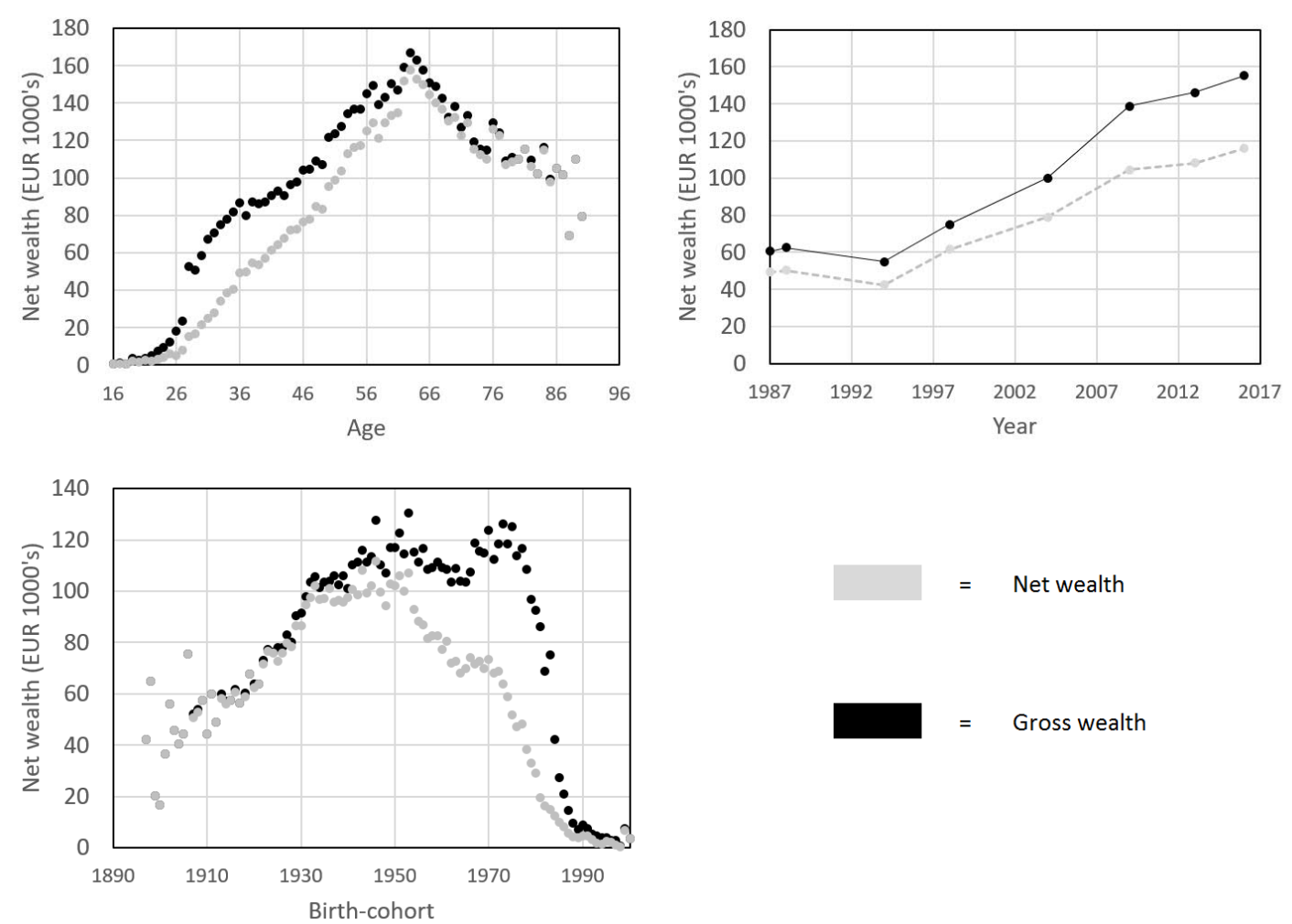

Figure 2. Stylised facts on median gross and net wealth age, year, and birth cohort. 
Age distribution shows that median wealth accumulates from the beginning of the life course until the retirement phase, where household income changes and wealth start to decline. Gross and net assets have been highest for those aged 55-65 and lowest for those under 25 . The other point is the distance between gross and net wealth, which diminishes as households decrease their debt. It seems that on average, debt is paid just before or at the brink of retirement age.

When periodical change is measured, median gross and net wealth has increased over time, after the 1990s economic shock, which temporarily had a wealth-diminishing impact. In addition, there is an observable increase in the gap of gross and net wealth, which indicates higher loan-taking in recent years. Regardless, overall wealth has risen significantly in absolute measures.

Cohort differences show how the subtraction between gross and net wealth reveals household debt. The most interesting point is the difference between gross and net wealth among cohorts from 1950 to 1990 . The diminishing distance between both wealth concepts during the ageing process shows how households pay up their debts. As observed in Figure 4, we see that young cohorts have the same level of gross wealth as their older counterparts, but most of the wealth is debt. As this debt is primarily allocated to dwelling ownership, how much of this loan-based wealth is also invested in financial assets? Thus, to clarify intercohort differences, we next calculate the predicted means for gross and net wealth and financial wealth.

\section{Long-term changes in gross wealth and net wealth between cohort and age groups}

Figure 3 shows the results of the marginal effects and interaction between cohort and period on gross wealth and net wealth. While period changes can illustrate within-year changes over cohorts, it is more reasonable to compare between cohorts in appropriate age groups. For example, the cohort born in 1970 is 24 years old in 1994; they should be 
compared to the cohort born in 1980, who turn 24 in 2004. These age interaction figures are placed after period interactions with the cohort for ease of comparison.

Overall, Figure 3 shows that the differences between gross wealth are relatively minor. Overall, the minimum predicted gross wealth is $€ 4,923$, and the highest is $€ 278,410$. As expected, the oldest cohorts of 1930-1949 hold the highest wealth trajectory, while the youngest remains at the bottom of the distribution. There is nothing spectacular in periodical changes in gross wealth, as it maintains logical progression; one such life event is retirement, where the wealth of the oldest cohort of 1930-1939 falls below the gross wealth of cohort of 1940-1949. As stated by the life cycle hypothesis, those who transition to retirement start using their accumulated wealth, or at least their wealth begins to decline, but they do not use it at the same rate as the hypothesis might suggest. There is a slight decline, although the deviation remains a minor event, and cannot be used as an argument for a trend.

A much higher variation is found in net wealth. The differences between net wealth and gross wealth illustrate the effect of debt, which is higher at the beginning of the life course. As expected, younger cohort groups have incrementally lower net wealth, as these groups have more debt than their older counterparts do. This can be explained by loan-taking for dwellings and other investments such as vehicles or other larger household acquisitions. Thus, net wealth is lower for younger cohorts, ranging from a low of $€ 31$ to the highest predicted wealth of $€ 200,156$. One interesting net wealth deviation can be attributed to cohort of 1960-1969, which seems to be 'lagging' from the beginning of the life course during labour market transition. One hypothesis for this is the economic shock of the 1990s, when this cohort group was 24-33 years old. Higher unemployment rates during this era and the volatile labour market situation could hinder earlier net wealth accumulation, as it could incentivise them to smooth out this period by loan-taking. 

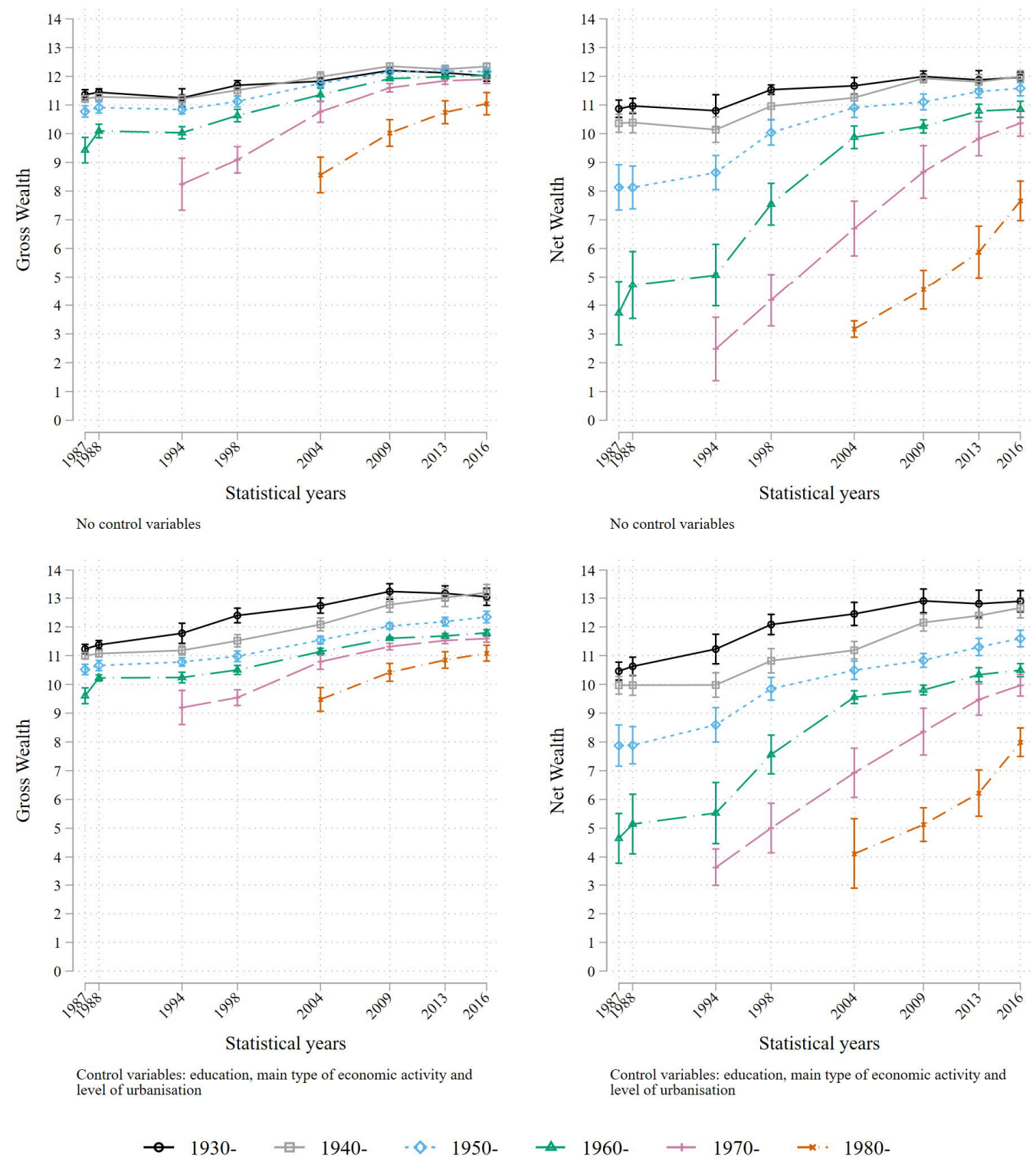

Figure 3. Predicted means of inverse hyperbolic sine gross wealth and net wealth by birth cohorts over the measurement period.

Figure 4 shows the interaction results between cohort and age on gross and net wealth. It seems that the cohort and age differences are mild, although small discrepancies are observable. For example, a cohort of 1980-1989 has a higher take-up on gross wealth than other cohorts, similar to the trajectory of the cohort of 1970-1979. When comparing cohorts at their comparable periodical age groups, we see that the cohort of 1970-1979 was 20 years old during the economic crisis during the 1990s, and a comparable cohort of 1980-1989 was aged 20 during the financial crisis of 2007-2008. When we observed net wealth accumulation 
between these two groups, we observe that the younger cohort had higher starting wealth, but slower take-up than the 1970-1979 cohort, although this difference was not statistically significant.
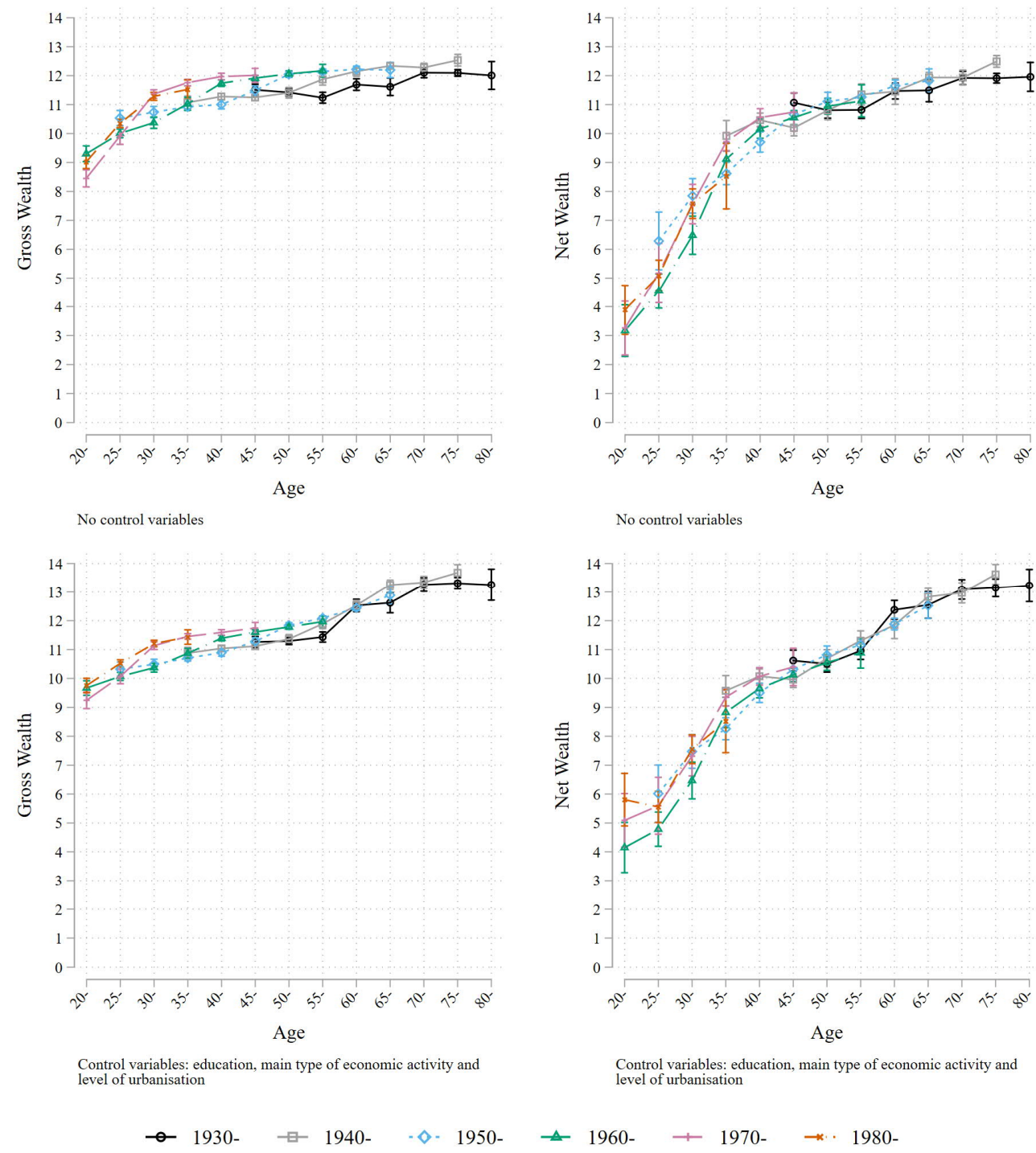

Figure 4. Predicted means of inverse hyperbolic sine gross wealth and net wealth by birth cohorts over age.

All other cohorts have more conservative accumulation of wealth, which can be counted as one of the few differences that are statistically significant. Although these variations disappear when measured in net wealth. In net wealth, we observe that all age and cohort effects remain similar throughout the life course, without any major statistical difference. It 
seems that when we consider debt and other factors, all cohorts experience wealth accumulation in an almost identical manner over the life course. This indicates that there is no 'generational divide' among cohort groups when considering age trajectories. It should be noted that this analysis does not reveal the future of wealth trajectories or estimates for the youngest cohorts, but on data level analysis, every generation seems to be equal in wealth accumulation over the life course.

We noted earlier that Figure 2 shows net wealth deviation for the 1960-1969 cohort. But when observing age and cohort interactions in Figure 3, these differences are not found. This suggests that these are indeed within-year variations, while cohort and age effects remain unchanged.

\section{Long-term changes in financial wealth between cohort and age groups}

Cohort differences in financial wealth draw an interesting division between the three cohort groups (Figure 5). The opening of the financial markets occurred during the 1980s and the first part of the 1990s. We can see this transition to different economic fields from the starting point and see how different cohorts have adopted new financial options available to them.

Overall, it seems that different cohorts have indeed been using new financial instruments. All cohorts at the first measurement point during 1987 own the same level of financial wealth, regardless of their age at the time, with the minor exception that younger cohorts have fewer resources available to invest in financial instruments. Regardless, it seems that the availability of these instruments maintains financial wealth levels at the same level regardless of age or cohort groups. 


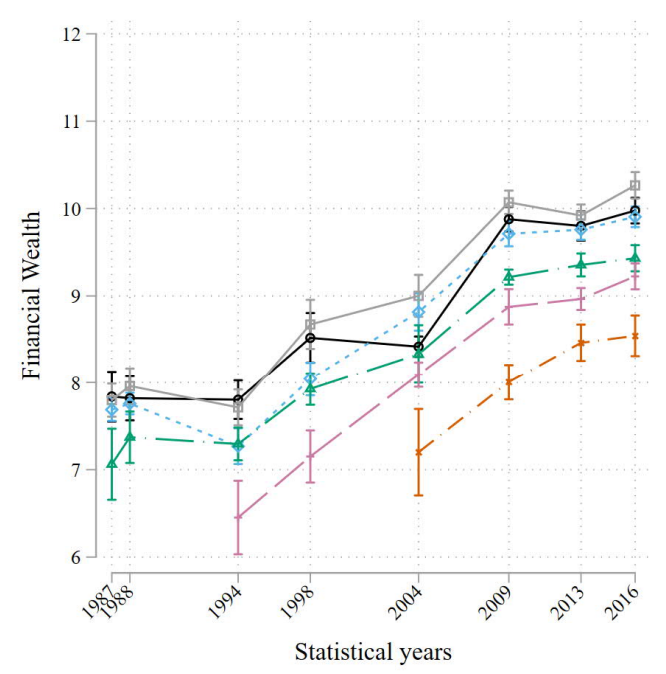

No control variables

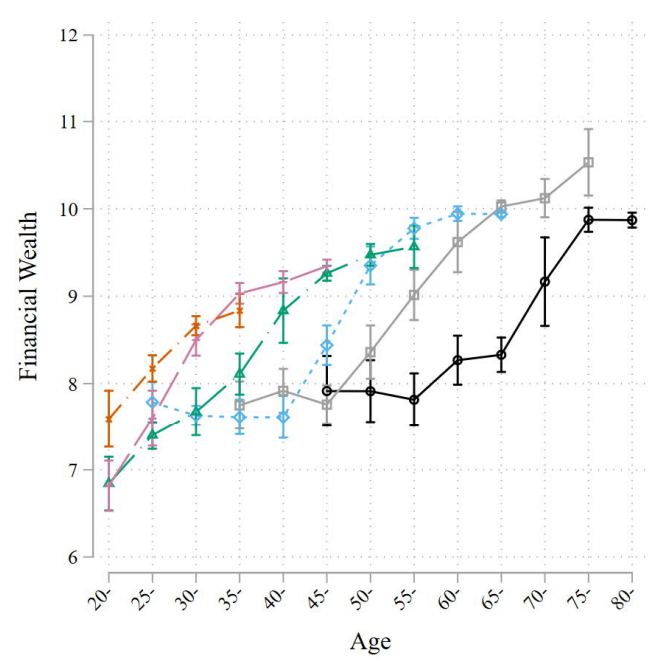

No control variables

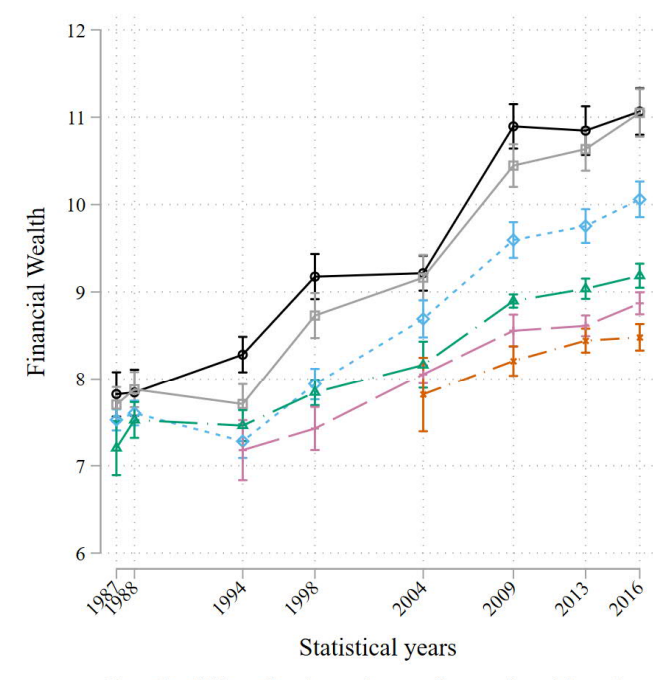

Control variables: education, main type of economic activity and level of urbanisation

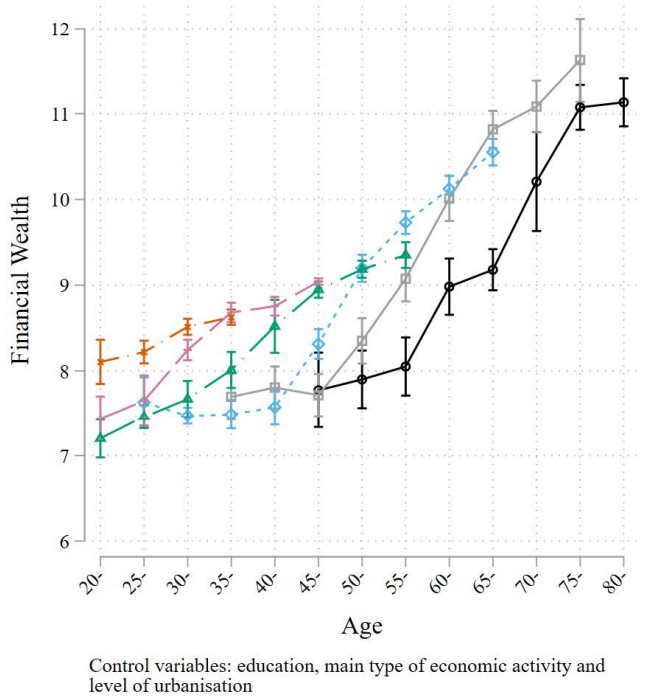

level of urbanisation

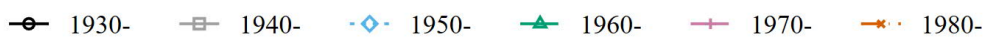

Figure 5. Predicted means of inverse hyperbolic sine financial wealth by birth cohorts over the measurement period and age.

All cohort groups increased their average investment over time, but in three tiers. First, in an absolute sense, cohorts born in 1930-1949 form a similar trend and own most of the financial wealth. One interesting point is that the cohort of 1940-1949 had a decrease in financial wealth between years 1987 and 1994. Second, the cohort of 1950-1959 was the second highest investor. In 1994, the cohort of 1950-1959 had a similar decrease in financial wealth. During this time, economic shocks occurred, which could be associated with the decrease and higher take-up in financial wealth investments. 
In monetary terms, the three cohort groupings have drastic differences in financial assets. For example, to compare the maximum width of the wealth gap in 2016, the first group of cohorts (1960-1989) holds approximately €2,400 of financial assets in comparison to the two oldest cohorts, who have accumulated 13 times more, up to approximately $€ 32,100$. This gap is not observed in the uncontrolled model, but when independent variables are introduced, we observe a widening financial wealth gap from a rather equal starting point.

Both cohorts were $34-44$ or $45-54$ years old, which is an interesting age period for decreasing financial assets. During economic shock, there are theories that suggest households aim to smoothen out the lack of income; for example, during unemployment, but usually the 45-54 age bracket has established their position in the labour market and has no need to compensate for this transition period. Still, this is something that would need further research, as our data cannot identify the mechanism behind this phenomenon.

Third, the youngest cohort, 1960-1989, has the lowest absolute numbers. Then again, the youngest group holds more assets from the starting age, which can be assumed to accumulate a higher revenue stream during the later stage of the life course if we make a linear assumption of the financial wealth trajectory. For example, the cohort of 1950-1959 holds only $€ 1,080$ in financial assets at the age of 25-29 years, while their younger counterparts at similar ages had almost double that of $€ 1,860$. This association can be seen in Figure 7.

When we observe representative age in relation to period, we see a more nuanced view. The lower panel of Figure 7 shows the interaction models between cohorts and age on financial wealth. Overall, cohort differences are inverse compared to gross wealth and net wealth estimates. Here, younger generations tend to invest more in financial wealth than older ones do. Again, the trajectory of said accumulation is milder than in the baby boomer cohorts, although lack of data does not make this a robust assessment. Still, the cohort of 
1950-1959 did not exceed the same total growth as 1940-1949, as the crossing point occurs in the 60-64 age bracket.

For example, comparing 2004 for the second highest investor group, the cohort of 19501959, with 1994 for the 1940-1949 cohort group, reveals that the younger cohort has invested more readily in financial assets, as its rates are higher than the older cohort's rates at the same age. All the cohorts had the same experience of the opening of the financial markets, which translates as earlier financial wealth accumulation, as seen above. Overall, it seems to start climbing earlier than before, compared to the older cohort's age range and those 45-55, which shows that younger generations are investing more in financial assets than their older counterparts. This support the hypothesis that the greater availability of said assets during the whole life course would make them more likely to be used by younger people.

\section{Conclusions}

The main objective of this study was to assess how inter-cohort wealth dynamics have changed over time, especially after institutional change such as the opening of financial markets. Overall, the life course hypothesis (Mayer, 2000, 2009) remains a valid framework, as wealth accumulation within the age variable remains constant until retirement age, while younger cohorts hold the same gross wealth level as older cohorts, but with a high level of indebtedness, illustrated by net wealth. From the period perspective, total wealth has been on the rise among all subgroups, although the amount of debt seems to be also increasing.

In our first hypothesis, we stated that long-term wealth differences have increased among cohorts, which is not supported by our results. The results show that inter-cohort wealth inequality has not increased over time, and all differences are attributed to within-year variations. This supports previous results related to economic fluctuations as variation increases between years, but shows that wealth accumulation does not seem to be hindered by 
economic circumstances in the long run (Attanasio et al., 1999; Cagetti, 2003; Karonen \& Niemelä, n.d.; Lusardi et al., 2017; Malmendier \& Nagel, 2011). Instead, financial wealth shows variations among three distinct investment groups, and higher investment interest can be associated with decreasing initial investment ages among younger cohorts. To extrapolate results in a linear fashion, young generations are more likely to accumulate more financial wealth than their older counterparts are, if the assumption of linearity is to be assumed. Thus, the null hypothesis is valid.

In the second hypothesis, we suggested that the gross, net, and financial wealth gaps between cohorts has increased. This is only partly supported, as inter-cohort gross and net wealth inequality has not increased over time, and all variations can be attributed to withinyear differences. The results are more in line with previous findings that suggest that assets before debt reduction have been more evenly distributed over age (Törmälehto, Matala, and Junes, 2018). In addition, the previous suggestion (Skopek et al., 2014) that highly egalitarian societies have high wealth inequality, and conversely, southern European countries exhibit comparatively low levels of wealth inequality, is not supported by our data. Instead, as a new finding, financial wealth shows variations among three distinct investment groups, and higher investment interest can be associated with decreasing initial investment ages among younger cohorts. More research is needed to reveal the mechanisms behind these trends.

Our last hypothesis states that after opening financial markets, investment in financial wealth has increased more in cohorts that have more resources. This is supported by our results, as financial wealth seems to be more popular among younger cohorts regardless of their high debt level, although older cohorts hold most of their assets. The cohort of 19401949 has the highest number of assets in absolute amounts due their age and resource accumulation during their life. It seems that younger cohorts embraced new financial instruments much more in early age than did their older counterparts. This seems to be an 
inverse of the previous hypothesis, that those who have fewer resources, such as young cohorts, would be more risk averse (Attanasio et al., 1999; Cagetti, 2003; Karonen \& Niemelä, n.d.; Lusardi et al., 2017; Malmendier \& Nagel, 2011). Overall, the results show that financial deregulation considerably increased investment in financial assets among all cohort groups.

As previous research has mainly focussed on age variations, our cohort approach contributed to the research field in several ways. When compared to the five main components of the previous studies illustrated in the introduction, we observe that wealth is indeed more concentrated than income, and is concentrated among those who have more income. The results show that when comparing wealth distribution between cohorts, the periodical differences are obvious but hold identical trends, and relative age groups between cohorts in certain periods show no differences in gross or net wealth, even when social background is controlled. In other words, while previous research shows the negative role of period profiles on different cohorts, we observe no such inequality development in gross and net wealth (see Lim \& Zeng, 2016). This finding in the Finnish context undermines Mayer's (2000, 2009) periodical shock hypothesis, as it seems that differences between cohorts return to average trends over time. Instead of financial wealth, we observe expanding differences among three cohort groupings associated with economic position, as the control variable creates this divide, which has not been previously captured. In addition to wealth discussion and the previous notion of uniform gross and net wealth trends, financial wealth can be estimated to be higher in younger cohorts as they can reap the benefits of a much longer timespan, where older generations started from a lower point of investment and had more time for financial accumulation. This observation calls for more research to determine whether access to greater resources, or the stability of certain occupational fields, acts as an incentive to invest in financial assets. 
The limitations of our study consist of internal data validity, where due to the sample we do not have the extremes of wealth distributions. However, data is not top- or bottom-coded, thus giving appropriate mean values for each cohort. Second, due to changes in wealth tax legislation, some of the information is gathered from surveys rather than registers. In the future, research should aim to gain access to accurate data from the financial sector, as accurate individual measures would truly give an opportunity to research wealth accumulation and intergenerational transmission. 


\section{References}

Attanasio OP, Banks J, Meghir C, and Weber G (1999) Humps and bumps in lifetime consumption. Journal of Business and Economic Statistics 17(1): 22-35. https://doi.org/10.2307/1392236.

Berloffa G and Villa P (2010) Differences in equivalent income across cohorts of households: evidence from Italy. Review of Income and Wealth 56(4): 693-714. https://doi.org/10.1111/j.1475-4991.2010.00403.x

Blomgren JK, Hiilamo H, Kangas O and Niemelä M (2014) Finland: Growing inequality with contested consequences in changing inequalities in rich countries. Changing Inequalities and Societal Impacts in Rich Countries: Thirty Countries' Experiences. Oxford: Oxford University Press, pp. 222-247.

Cagetti M (2003) Wealth accumulation over the life cycle and precautionary savings. Journal of Business and Economic Statistics 21(3): 339-353.

Charles KK and Hurst E (2003) The correlation of wealth across generations. Journal of Political Economy 111(6): 1155-1182, https://doi.org/10.1086/378526.

Cole S, Shastry GK, Tobacman J, et al. (2008) If you are so smart why aren't you rich? The effects of education financial literacy and cognitive ability on financial market participation. Cambridge, MA: Harvard Business School.

Conley D (2001) Capital for college: Parental assets and postsecondary schooling. Sociology of Education 74(1): 59-72, https://doi.org/10.2307/2673145.

Conley D and Glauber R (nd) Wealth Mobility and volatility in black and white. Center for American Progress. https://wwwamericanprogressorg/issues/economy/reports/2008/07/29/4662/wealthmobility-and-volatility-in-black-and-white/ (retrieved 5 December 2019).

Conley D and Ryvicker M (2005) The price of female headship: Gender inheritance and wealth accumulation in the United States. Journal of Income Distribution 13(3-4): 3-3.

Cribb J (2019) Intergenerational differences in income and wealth: Evidence from Britain, Fiscal Studies 40(3) 275-299. 
Crossley TF, O’Dea C, Crawford R, et al. (2016) Household wealth in Great Britain: Distribution composition and changes 2006-12. Fiscal Studies 37: 35-54.

Díaz-Giménez J, Quadrini V, and Ríos-Rull J-V (1997) Dimensions of inequality: Facts on the US distributions of earnings income and wealth. Quarterly Review 21(1): 3-21.

Doepke M and Schneider M (2006) Inflation and the redistribution of nominal wealth. Journal of Political Economy 114(6), 1069-1097, https://doi.org/10.1086/508379.

Douglas M and Isherwood BC (1996) The world of goods: Towards an anthropology of consumption. Psychology Press.

Feng C, Wang H, Lu N, at al. (2014) Log-transformation and its implications for data analysis. Shanghai Archives of Psychiatry 26(2): 105-109.

Friedline T, Masa RD, and Chowa GA (2015) Transforming wealth: Using the inverse hyperbolic sine (IHS) and splines to predict youth's math achievement. Social Science Research 49: 264-287. https://doi.org/101016/jss.research201408018

Gittleman M and Wolff EN (2004) Racial differences in patterns of wealth accumulation. The Journal of Human Resources 39(1): 193-227. https://doi.org/10.2307/3559010.

Green L (2010) Understanding the life course: Sociological and psychological perspectives. Polity.

Hall M and Crowder K (2011) Extended-family resources and racial inequality in the transition to homeownership. Social Science Research 40(6): 1534-1546. https://doi.org/101016/jss.research201107002.

Hällsten M and Pfeffer F T (2017) Grand advantage: Family wealth and grandchildren's educational achievement in Sweden. American Sociological Review 82(2): 328-360. https://doi.org/10.1177/0003122417695791

Hanna SD, Wang C, and Yuh Y (2010) Racial/ethnic differences in high return investment ownership: A decomposition analysis (SSRN Scholarly Paper ID 1888416). Social Science Research Network, https://papersssrn.com/abstract=1888416.

Hansen MN (2014) Self-made wealth or family wealth? Changes in intergenerational wealth mobility. Social Forces 93(2): 457-481. https://doi.org/10.1093/sf/sou078. 
Hastings JS, Madrian BC, and Skimmyhorn WL (2013) Financial literacy financial education and economic outcomes. Annual Review of Economics 5(1): 347-373. https://doi.org/10.1146/annurev-economics-082312-125807.

Hurst E, Luoh MC, Stafford FP, and Gale WG (1998) The wealth dynamics of American families 1984-94. Brookings Papers on Economic Activity 1998(1): 267-337. https://doi.org/10.2307/2534673.

Hutchison ED (2010). A life course perspective. Dimensions of Human Behavior: The Changing Life Course 4, 3-38.

Iacoviello M and Pavan M (2013) Housing and debt over the life cycle and over the business cycle. Journal of Monetary Economics 60(2): 221-238. https://doi.org/10.1016/j.jmoneco.2012.10.020.

Jantti M, Sierminska E, and Smeeding T (2008) The Joint distribution of household income and wealth: Evidence from the Luxembourg wealth study (No 65; OECD Social Employment and Migration Working Papers). OECD Publishing. https://ideasrepecorg/p/oec/elsaab/65-enhtml Jappelli T (1999) The age-wealth profile and the life-cycle hypothesis: A cohort analysis with a time series of cross-sections of Italian households. Review of Income and Wealth 45(1): 57-75. https://doi.org/10.1111/j.1475-4991.1999.tb00312.x.

Kahneman D and Riis J (2005) Living and thinking about it: Two perspectives on life. The science of well-being 1, pp. 285-304.

Karonen E and Niemelä M (nd) Life course perspective on economic shocks and income inequality through age-period-cohort analysis: Evidence from Finland. Review of Income and Wealth 66(2):287-310. https://doi.org/10.1111/roiw.12409.

Keister LA (2003) Religion and wealth: The role of religious affiliation and participation in early adult asset accumulation. Social Forces 82(1): 175-207. h ttps://doi.org/10.1353/sof.2003.0094.

Keister LA (2004) Race, family structure, and wealth: The effect of childhood family on adult asset ownership. Sociological Perspectives 47(2): 161-187. https://doi.org/10.1525/sop.2004.47.2.161. 
Kim EJ, Hanna SD, Chatterjee S, and Lindamood S (2012) Who among the elderly owns stocks? The Role of cognitive ability and bequest motive. Journal of Family and Economic Issues 33(3) 338-352. https://doi.org/10.1007/s10834-012-9295-2

Lim GC and Zeng Q (2016) Consumption, income and wealth: Evidence from Age cohort and period elasticities. Review of Income and Wealth 62(3): 489-508. https://doi.org/10.1111/roiw.12182

Lusardi A, Michaud P-C, and Mitchell OS (2017) Optimal financial knowledge and wealth inequality. Journal of Political Economy 125(2) 431-477.

Malmendier U and Nagel S (2011) Depression babies: Do macroeconomic experiences affect risk taking? The Quarterly Journal of Economics 126(1): 373-416.

Mayer KU (2000) Promises fulfilled? A review of 20 years of life course research. European Journal of Sociology 41(02): 259-282.

Mayer KU (2009) New directions in life course research. Annual Review of Sociology 35(1): 413433. https://doi.org/10.1146/annurev.soc.34.040507.134619.

McKernan S-M, Ratcliffe C, Simms M, et al. (2014) Do racial disparities in private transfers help explain the racial wealth gap? New evidence from longitudinal data. Demography 51(3): 949974. https://doi.org/10.1007/s13524-014-0296-7

Mulligan CB (1997) Parental Priorities and Economic Inequality. Chicago: University of Chicago Press.

Pence K (2006) The Role of wealth transformations: An application to estimating the effect of tax incentives on saving. The BE Journal of Economic Analysis and Policy 5(1): 1-26.

Pfeffer FT and Killewald A (2018) Generations of advantage multigenerational correlations in family wealth. Social Forces 96(4): 1411-1442. https://doi.org/10.1093/sf/sox086.

Prix I and Pfeffer FT (2017) Does Donald need Uncle Scrooge? Extended family wealth and children's educational attainment in the United States. Social Inequality Across the Generations. Edward Elgar Publishing. https://www.elgaronline.com/view/edcoll/9781786432551/9781786432551.00013.xml 
Semyonov M and Lewin-Epstein N (2013) Ways to richness: Determination of household wealth in 16 countries. European Sociological Review 29(6): 1134-1148.

https://doi.org/10.1093/esr/jct001.

Sierminska E and Takhtamanova Y (2007) Wealth effects out of financial and housing wealth: Cross country and age group comparisons (No 2007-01; Working Paper Series). Federal Reserve Bank of San Francisco, https://ideas.repec.org/p/fip/fedfwp/2007-01.html

Skopek N, Buchholz S, and Blossfeld H-P (2014) National patterns of income and wealth inequality. International Journal of Comparative Sociology 55(6): 463-488. https://doi.org/10.1177/0020715214565674.

Törmälehto V-M (2018a) Varallisuuserot kasvussa, tuloerot vakaat? Tieto \& Trendit. https://www.stat.fi/tietotrendit/artikkelit/2018/varallisuuserot-kasvussa-tuloerotvakaat/?listing=simple (accessed 26 March 2020).

Törmälehto V-M (2018b) Tilastokeskus - Kotitalouksien varallisuus 2016 Retrieved March 262020 from https://wwwstatfi/til/vtutk/2016/vtutk_2016_2018-06-05_tie_001_fihtml.

Wolff EN (1998) Recent trends in the size distribution of household wealth. Journal of Economic Perspectives 12(3): 131-150. https://doi.org/10.1257/jep.12.3.131.

Yamokoski A and Keister LA (2006) The wealth of single women: Marital status and parenthood in the asset accumulation of young baby boomers in the United States. Feminist Economics 12(1-2): 167-194. https://doi.org/10.1080/13545700500508478. 


\section{Appendix}

Table A.1. Predicted values for gross, net, and financial wealth, age*cohort interactions.

\begin{tabular}{|c|c|c|c|c|c|c|}
\hline & $\begin{array}{c}\text { Gross } \\
\text { wealth } \\
\text { uncontrolled }\end{array}$ & $\begin{array}{c}\text { Gross } \\
\text { wealth } \\
\text { controlled }\end{array}$ & $\begin{array}{c}\text { Net } \\
\text { wealth } \\
\text { uncontrolled }\end{array}$ & $\begin{array}{c}\text { Net } \\
\text { wealth } \\
\text { controlled }\end{array}$ & $\begin{array}{c}\text { Financial } \\
\text { wealth } \\
\text { uncontrolled }\end{array}$ & $\begin{array}{l}\text { Financial } \\
\text { wealth } \\
\text { controlled }\end{array}$ \\
\hline \multirow{3}{*}{$1930-1939 * 45-49$} & 11.51 & 11.26 & 11.07 & 10.50 & 7.914 & 7.774 \\
\hline & $(0.00592)$ & $(0.0202)$ & $(0.0419)$ & $(0.0845)$ & $(0.205)$ & $(0.224)$ \\
\hline & 49853.94 & 38826.29 & 32107.75 & 18157.75 & 1367.66 & 1188.98 \\
\hline \multirow[t]{3}{*}{$1930-1939 * 50-54$} & 11.42 & 11.29 & 10.81 & 10.45 & 7.913 & 7.901 \\
\hline & $(0.108)$ & $(0.112)$ & $(0.227)$ & $(0.232)$ & $(0.181)$ & $(0.172)$ \\
\hline & 45563.07 & 40008.72 & 24756.73 & 17272.19 & 1366.29 & 1349.99 \\
\hline \multirow[t]{3}{*}{$1930-1939 * 55-59$} & 11.24 & 11.43 & 10.82 & 10.84 & 7.815 & 8.051 \\
\hline & $(0.132)$ & $(0.133)$ & $(0.216)$ & $(0.197)$ & $(0.154)$ & $(0.173)$ \\
\hline & 38057.48 & 46020.99 & 25005.54 & 25510.68 & 1238.74 & 1568.46 \\
\hline \multirow[t]{3}{*}{$1930-1939 * 60-64$} & 11.69 & 12.53 & 11.47 & 12.23 & 8.268 & 8.982 \\
\hline & $(0.0490)$ & $(0.0988)$ & $(0.0702)$ & $(0.147)$ & $(0.143)$ & $(0.167)$ \\
\hline & 59686.00 & 138254.69 & 47899.14 & 102421.59 & 1948.57 & 3979.26 \\
\hline \multirow[t]{3}{*}{$1930-1939 * 65-69$} & 11.62 & 12.62 & 11.49 & 12.42 & 8.330 & 9.180 \\
\hline & $(0.106)$ & $(0.127)$ & $(0.160)$ & $(0.200)$ & $(0.100)$ & $(0.122)$ \\
\hline & 55650.86 & 151274.72 & 48866.77 & 123853.27 & 2073.21 & 4850.58 \\
\hline \multirow[t]{3}{*}{$1930-1939 * 70-74$} & 12.10 & 13.27 & 11.92 & 13.04 & 9.166 & 10.21 \\
\hline & $(0.0730)$ & $(0.135)$ & $(0.0777)$ & $(0.185)$ & $(0.259)$ & $(0.294)$ \\
\hline & 89935.93 & 289772.91 & 75120.80 & 230234.31 & 4783.14 & 13586.78 \\
\hline \multirow[t]{3}{*}{$1930-1939 * 75-79$} & 12.09 & 13.31 & 11.91 & 13.11 & 9.875 & 11.07 \\
\hline & $(0.0495)$ & $(0.132)$ & $(0.130)$ & $(0.227)$ & $(0.0703)$ & $(0.134)$ \\
\hline & 89041.05 & 301598.76 & 74373.33 & 246928.18 & 9719.14 & 32107.75 \\
\hline \multirow[t]{3}{*}{$1930-1939 * 80-84$} & 12.01 & 13.26 & 11.96 & 13.22 & 9.871 & 11.13 \\
\hline & $(0.232)$ & $(0.335)$ & $(0.249)$ & $(0.404)$ & $(0.0436)$ & $(0.143)$ \\
\hline & 82195.25 & 286889.61 & 78186.54 & 275640.51 & 9680.34 & 34093.19 \\
\hline \multirow{3}{*}{$1940-1949 * 35-39$} & 11.07 & 10.88 & 9.918 & 9.616 & 7.751 & 7.697 \\
\hline & $(0.108)$ & $(0.109)$ & $(0.189)$ & $(0.251)$ & $(0.139)$ & $(0.138)$ \\
\hline & 32107.75 & 26551.80 & 10146.18 & 7501.46 & 1161.95 & 1100.87 \\
\hline \multirow[t]{3}{*}{$1940-1949 * 40-44$} & 11.28 & 11.04 & 10.47 & 10.02 & 7.917 & 7.806 \\
\hline & $(0.0637)$ & $(0.0613)$ & $(0.221)$ & $(0.208)$ & $(0.128)$ & $(0.125)$ \\
\hline & 39610.63 & 31158.83 & 17621.11 & 11235.71 & 1371.76 & 1227.64 \\
\hline \multirow[t]{3}{*}{$1940-1949 * 45-49$} & 11.25 & 11.12 & 10.20 & 9.935 & 7.759 & 7.716 \\
\hline & $(0.0626)$ & $(0.0590)$ & $(0.179)$ & $(0.144)$ & $(0.112)$ & $(0.127)$ \\
\hline & 38439.96 & 33753.95 & 13451.59 & 10320.14 & 1171.28 & 1121.98 \\
\hline $1940-1949 * 50-54$ & 11.41 & 11.37 & 10.80 & 10.60 & 8.360 & 8.350 \\
\hline & $(0.0854)$ & $(0.0681)$ & $(0.204)$ & $(0.170)$ & $(0.156)$ & $(0.135)$ \\
\hline & 45109.71 & 43340.93 & 24510.40 & 20067.41 & 2136.34 & 2115.09 \\
\hline $1940-1949 * 55-59$ & 11.87 & 11.89 & 11.35 & 11.19 & 9.015 & 9.075 \\
\hline & $(0.125)$ & $(0.113)$ & $(0.184)$ & $(0.170)$ & $(0.147)$ & $(0.135)$ \\
\hline & 71457.11 & 72900.65 & 42482.73 & 36201.39 & 4112.77 & 4367.09 \\
\hline $1940-1949 * 60-64$ & 12.15 & 12.54 & 11.45 & 11.70 & 9.620 & 10.01 \\
\hline & $(0.0979)$ & $(0.0809)$ & $(0.163)$ & $(0.148)$ & $(0.176)$ & $(0.134)$ \\
\hline & 94547.04 & 139644.16 & 46950.67 & 60285.86 & 7531.52 & 11123.92 \\
\hline $1940-1949 * 65-69$ & 12.34 & 13.25 & 11.94 & 12.71 & 10.02 & 10.82 \\
\hline & $(0.0326)$ & $(0.107)$ & $(0.0768)$ & $(0.137)$ & $(0.0357)$ & $(0.110)$ \\
\hline & 114330.97 & 284035.02 & 76638.35 & 165520.91 & 11235.72 & 25005.54 \\
\hline $1940-1949 * 70-74$ & 12.28 & 13.34 & 11.93 & 12.91 & 10.12 & 11.08 \\
\hline & $(0.0740)$ & $(0.135)$ & $(0.0931)$ & $(0.177)$ & $(0.112)$ & $(0.154)$ \\
\hline & 107672.86 & 310783.82 & 75875.78 & 202167.70 & 12417.39 & 32430.44 \\
\hline $1940-1949 * 75-79$ & 12.53 & 13.68 & 12.49 & 13.59 & 10.53 & 11.63 \\
\hline & $(0.0306)$ & $(0.131)$ & $(0.0316)$ & $(0.187)$ & $(0.194)$ & $(0.249)$ \\
\hline & 138254.68 & 436634.97 & 132833.64 & 399054.31 & 18710.73 & 56210.16 \\
\hline $1950-1959 * 25-29$ & 10.54 & 10.32 & 6.289 & 6.190 & 7.785 & 7.631 \\
\hline & $(0.109)$ & $(0.154)$ & $(0.160)$ & $(0.253)$ & $(0.119)$ & $(0.149)$ \\
\hline & 18898.78 & 15166.62 & 269.31 & 243.92 & 1202.13 & 1030.55 \\
\hline $1950-1959 * 30-34$ & 10.74 & 10.49 & 7.848 & 7.647 & 7.632 & 7.472 \\
\hline & $(0.102)$ & $(0.0892)$ & $(0.382)$ & $(0.350)$ & $(0.0573)$ & $(0.0497)$ \\
\hline & 23083.02 & 17977.07 & 1280.30 & 1047.17 & 1031.58 & 879.05 \\
\hline $1950-1959 * 35-39$ & 10.93 & 10.71 & 8.619 & 8.372 & 7.615 & 7.490 \\
\hline & $(0.104)$ & $(0.0809)$ & $(0.254)$ & $(0.188)$ & $(0.103)$ & $(0.0867)$ \\
\hline & 27913.13 & 22400.81 & 2767.92 & 2162.13 & 1014.19 & 895.02 \\
\hline $1950-1959 * 40-44$ & 11.00 & 10.89 & 9.706 & 9.563 & 7.614 & 7.574 \\
\hline & $(0.0570)$ & $(0.0658)$ & $(0.146)$ & $(0.147)$ & $(0.125)$ & $(0.106)$ \\
\hline & 29937.07 & 26818.64 & 8207.90 & 7114.23 & 1013.18 & 973.45 \\
\hline $1950-1959 * 45-49$ & 11.49 & 11.28 & 10.66 & 10.30 & 8.439 & 8.314 \\
\hline & $(0.0784)$ & $(0.0507)$ & $(0.188)$ & $(0.161)$ & $(0.115)$ & $(0.0880)$ \\
\hline & 48866.76 & 39610.63 & 21308.31 & 14866.31 & 2311.96 & 2040.30 \\
\hline $1950-1959 * 50-54$ & 12.05 & 11.84 & 11.11 & 10.72 & 9.352 & 9.197 \\
\hline & $(0.0536)$ & $(0.0401)$ & $(0.138)$ & (0.109) & $(0.111)$ & $(0.0807)$ \\
\hline
\end{tabular}




\begin{tabular}{|c|c|c|c|c|c|c|}
\hline \multirow{4}{*}{$1950-1959 * 55-59$} & 85549.70 & 69345.24 & 33418.09 & 22625.95 & 5760.92 & 4933.74 \\
\hline & 12.15 & 12.09 & 11.26 & 11.07 & 9.777 & 9.730 \\
\hline & $(0.0650)$ & $(0.0601)$ & $(0.0940)$ & $(0.0786)$ & $(0.0615)$ & $(0.0672)$ \\
\hline & 94547.04 & 89041.05 & 38826.28 & 32107.75 & 8811.85 & 8407.27 \\
\hline \multirow{3}{*}{$1950-1959 * 60-64$} & 12.22 & 12.44 & 11.65 & 11.73 & 9.944 & 10.12 \\
\hline & $(0.0356)$ & $(0.0610)$ & $(0.138)$ & $(0.175)$ & $(0.0423)$ & $(0.0786)$ \\
\hline & 101402.47 & 126355.26 & 57345.68 & 62121.83 & 10413.44 & 12417.38 \\
\hline \multirow[t]{3}{*}{$1950-1959 * 65-69$} & 12.20 & 12.89 & 11.83 & 12.36 & 9.939 & 10.55 \\
\hline & $(0.185)$ & $(0.150)$ & $(0.162)$ & $(0.134)$ & $(0.0157)$ & $(0.0787)$ \\
\hline & 99394.57 & 198164.50 & 68655.24 & 116640.61 & 10361.50 & 19088.71 \\
\hline \multirow[t]{3}{*}{$1960-1969 * 20-24$} & 9.301 & 9.669 & 3.171 & 4.125 & 6.843 & 7.201 \\
\hline & $(0.147)$ & $(0.112)$ & $(0.398)$ & $(0.361)$ & $(0.157)$ & $(0.114)$ \\
\hline & 5474.48 & 7909.76 & 11.89 & 30.92 & 468.64 & 670.38 \\
\hline \multirow[t]{3}{*}{$1960-1969 * 25-29$} & 10.01 & 10.07 & 4.549 & 4.889 & 7.399 & 7.460 \\
\hline & $(0.100)$ & $(0.0592)$ & $(0.418)$ & $(0.372)$ & $(0.0795)$ & $(0.0705)$ \\
\hline & 11123.91 & 11811.78 & 47.26 & 66.40 & 817.17 & 868.57 \\
\hline \multirow[t]{3}{*}{$1960-1969 * 30-34$} & 10.37 & 10.37 & 6.486 & 6.681 & 7.674 & 7.670 \\
\hline & $(0.0822)$ & $(0.0676)$ & $(0.295)$ & $(0.265)$ & $(0.140)$ & $(0.109)$ \\
\hline & 15944.23 & 15944.23 & 327.94 & 398.55 & 1075.83 & 1071.54 \\
\hline \multirow[t]{3}{*}{$1960-1969 * 35-39$} & 11.03 & 10.87 & 9.119 & 9.002 & 8.108 & 8.011 \\
\hline & $(0.133)$ & $(0.102)$ & $(0.235)$ & $(0.180)$ & $(0.120)$ & $(0.107)$ \\
\hline & 30848.79 & 26287.60 & 4563.53 & 4059.65 & 1660.46 & 1506.96 \\
\hline \multirow[t]{3}{*}{$1960-1969 * 40-44$} & 11.74 & 11.39 & 10.17 & 9.676 & 8.835 & 8.520 \\
\hline & $(0.0890)$ & $(0.0780)$ & $(0.153)$ & $(0.107)$ & $(0.188)$ & $(0.158)$ \\
\hline & 62746.17 & 44216.47 & 13054.03 & 7965.32 & 3435.27 & 2507.02 \\
\hline \multirow[t]{3}{*}{$1960-1969 * 45-49$} & 11.91 & 11.61 & 10.55 & 10.11 & 9.263 & 8.948 \\
\hline & $(0.0386)$ & $(0.0365)$ & $(0.141)$ & $(0.132)$ & $(0.0434)$ & $(0.0480)$ \\
\hline & 74373.33 & 55097.12 & 19088.71 & 12293.83 & 5270.35 & 3846.24 \\
\hline \multirow[t]{3}{*}{$1960-1969 * 50-54$} & 12.06 & 11.78 & 10.94 & 10.51 & 9.473 & 9.185 \\
\hline & $(0.0401)$ & $(0.0325)$ & $(0.108)$ & $(0.0805)$ & $(0.0633)$ & $(0.0509)$ \\
\hline & 86409.49 & 65306.88 & 28193.67 & 18340.23 & 6501.92 & 4874.88 \\
\hline \multirow[t]{3}{*}{$1960-1969 * 55-59$} & 12.17 & 11.97 & 11.13 & 10.81 & 9.566 & 9.351 \\
\hline & $(0.00440)$ & $(0.0179)$ & $(0.150)$ & $(0.162)$ & $(0.124)$ & $(0.0764)$ \\
\hline & 96457.02 & 78972.33 & 34093.18 & 24756.73 & 7135.60 & 5755.16 \\
\hline \multirow[t]{3}{*}{$1970-1979 * 20-24$} & 8.450 & 9.244 & 3.260 & 4.324 & 6.818 & 7.439 \\
\hline & $(0.246)$ & $(0.185)$ & $(0.428)$ & $(0.372)$ & $(0.147)$ & $(0.133)$ \\
\hline & 2337.54 & 5171.16 & 13.01 & 37.74 & 457.08 & 850.52 \\
\hline \multirow[t]{3}{*}{$1970-1979 * 25-29$} & 9.913 & 10.07 & 5.172 & 5.780 & 7.599 & 7.650 \\
\hline & $(0.180)$ & $(0.151)$ & $(0.433)$ & $(0.377)$ & $(0.163)$ & $(0.151)$ \\
\hline & 10095.57 & 11811.78 & 88.13 & 161.87 & 998.09 & 1050.32 \\
\hline $1970-1979 * 30-34$ & 11.36 & 11.14 & 7.564 & 7.334 & 8.498 & 8.244 \\
\hline & $(0.0697)$ & $(0.0502)$ & $(0.351)$ & $(0.337)$ & $(0.0912)$ & $(0.0610)$ \\
\hline & 42909.68 & 34435.82 & 963.76 & 765.74 & 2452.47 & 1902.36 \\
\hline $1970-1979 * 35-39$ & 11.76 & 11.45 & 9.720 & 9.373 & 9.032 & 8.681 \\
\hline & $(0.0532)$ & $(0.0618)$ & $(0.168)$ & $(0.150)$ & $(0.0603)$ & $(0.0578)$ \\
\hline & 64013.72 & 46950.67 & 8323.62 & 5883.18 & 4183.28 & 2944.96 \\
\hline $1970-1979 * 40-44$ & 11.97 & 11.59 & 10.55 & 10.04 & 9.162 & 8.754 \\
\hline & $(0.0566)$ & $(0.0448)$ & $(0.221)$ & $(0.193)$ & $(0.0639)$ & $(0.0556)$ \\
\hline & 78972.33 & 54006.13 & 19088.72 & 11462.69 & 4764.04 & 3167.99 \\
\hline $1970-1979 * 45-49$ & 12.01 & 11.75 & 10.74 & 10.34 & 9.344 & 9.042 \\
\hline & $(0.0238)$ & $(0.0149)$ & $(0.0689)$ & $(0.0656)$ & $(0.0381)$ & $(0.0194)$ \\
\hline & 82195.25 & 63376.77 & 23083.02 & 15473.01 & 5715.01 & 4225.33 \\
\hline $1980-1989 * 20-24$ & 9.021 & 9.756 & 3.894 & 4.806 & 7.593 & 8.105 \\
\hline & $(0.210)$ & $(0.145)$ & $(0.241)$ & $(0.340)$ & $(0.166)$ & $(0.131)$ \\
\hline & 4137.52 & 8628.73 & 24.54 & 61.11 & 992.12 & 1655.49 \\
\hline $1980-1989 * 25-29$ & 10.35 & 10.52 & 5.083 & 5.525 & 8.173 & 8.220 \\
\hline & $(0.117)$ & $(0.0923)$ & $(0.272)$ & $(0.259)$ & $(0.0768)$ & $(0.0679)$ \\
\hline & 15628.52 & 18524.56 & 80.62 & 125.44 & 1771.97 & 1857.25 \\
\hline $1980-1989 * 30-34$ & 11.28 & 11.21 & 7.577 & 7.731 & 8.662 & 8.515 \\
\hline & $(0.0829)$ & $(0.0728)$ & $(0.121)$ & $(0.119)$ & $(0.0555)$ & $(0.0477)$ \\
\hline & 39610.63 & 36932.70 & 976.38 & 1138.93 & 2889.54 & 2494.52 \\
\hline $1980-1989 * 35-39$ & 11.52 & 11.43 & 8.527 & 8.540 & 8.836 & 8.627 \\
\hline & $(0.193)$ & $(0.0825)$ & $(0.227)$ & $(0.0915)$ & $(0.0971)$ & $(0.0455)$ \\
\hline & 50354.98 & 46020.98 & 2524.63 & 2557.67 & 3438.71 & 2790.15 \\
\hline $\mathrm{N}$ & 48935 & 48935 & 48935 & 48935 & 48935 & 48935 \\
\hline
\end{tabular}

Standard errors in parentheses.
Note: All predicted values are statistically significant $(\mathrm{p}<0.001)$, which are not marked in the results table to make it easy to read.

Note 2: We removed cohort*age and cohort*period interactions, which contain zero values as certain combinations cannot exist due to APC correlation.

Note 3: We applied the inverse function, $\frac{1}{2}(\exp (\beta x)+\exp (-\beta x))$, to obtain a more intuitive interpretation below each predicted value, under standard errors. 
Table A.2. Predicted values for gross. net and financial wealth. cohort*period interactions.

\begin{tabular}{|c|c|c|c|c|c|c|}
\hline & $\begin{array}{c}\text { Gross } \\
\text { wealth } \\
\text { uncontrolled }\end{array}$ & $\begin{array}{c}\text { Gross } \\
\text { wealth } \\
\text { controlled }\end{array}$ & $\begin{array}{c}\text { Net } \\
\text { wealth } \\
\text { uncontrolled }\end{array}$ & $\begin{array}{c}\text { Net } \\
\text { wealth } \\
\text { controlled }\end{array}$ & $\begin{array}{c}\text { Financial } \\
\text { wealth } \\
\text { uncontrolled }\end{array}$ & $\begin{array}{c}\text { Financial } \\
\text { wealth } \\
\text { controlled }\end{array}$ \\
\hline \multirow[t]{3}{*}{$1930-1939 * 1987$} & 11.36 & 11.23 & 10.87 & 10.46 & 7.840 & 7.821 \\
\hline & $(0.0888)$ & $(0.0829)$ & $(0.154)$ & $(0.159)$ & $(0.147)$ & $(0.132)$ \\
\hline & 42909.68 & 37678.79 & 26287.60 & 17445.77 & 1270.10 & 1246.19 \\
\hline \multirow[t]{3}{*}{$1930-1939 * 1988$} & 11.44 & 11.37 & 10.97 & 10.63 & 7.819 & 7.840 \\
\hline & $(0.0627)$ & $(0.0772)$ & $(0.135)$ & $(0.163)$ & $(0.129)$ & $(0.137)$ \\
\hline & 46483.50 & 43340.93 & 29052.29 & 20678.56 & 1243.70 & 1270.10 \\
\hline \multirow[t]{3}{*}{$1930-1939 * 1994$} & 11.25 & 11.78 & 10.80 & 11.23 & 7.803 & 8.282 \\
\hline & $(0.161)$ & $(0.178)$ & $(0.284)$ & $(0.262)$ & $(0.113)$ & $(0.104)$ \\
\hline & 38439.95 & 65306.88 & 24510.40 & 37678.79 & 1223.96 & 1976.04 \\
\hline \multirow[t]{3}{*}{$1930-1939 * 1998$} & 11.69 & 12.40 & 11.53 & 12.08 & 8.520 & 9.176 \\
\hline & $(0.0827)$ & $(0.129)$ & $(0.0844)$ & $(0.179)$ & $(0.145)$ & $(0.132)$ \\
\hline & 59686.00 & 121400.80 & 50861.05 & 88155.08 & 2507.02 & 4831.21 \\
\hline \multirow[t]{3}{*}{$1930-1939 * 2004$} & 11.83 & 12.74 & 11.67 & 12.45 & 8.419 & 9.215 \\
\hline & $(0.0716)$ & $(0.134)$ & $(0.147)$ & $(0.205)$ & $(0.0594)$ & $(0.102)$ \\
\hline & 68655.24 & 170561.77 & 58504.14 & 127625.16 & 2266.18 & 5023.35 \\
\hline \multirow[t]{3}{*}{$1930-1939 * 2009$} & 12.20 & 13.23 & 11.99 & 12.90 & 9.878 & 10.90 \\
\hline & $(0.0501)$ & $(0.137)$ & $(0.0973)$ & $(0.211)$ & $(0.0715)$ & $(0.130)$ \\
\hline & 99394.57 & 278410.74 & 80567.67 & 200156.09 & 9748.34 & 27088.18 \\
\hline \multirow[t]{3}{*}{$1930-1939 * 2013$} & 12.12 & 13.16 & 11.88 & 12.80 & 9.801 & 10.85 \\
\hline & $(0.0624)$ & $(0.133)$ & $(0.163)$ & $(0.240)$ & $(0.0856)$ & $(0.142)$ \\
\hline & 91752.75 & 259588.46 & 72175.27 & 181108.72 & 9025.89 & 25767.07 \\
\hline \multirow[t]{3}{*}{$1930-1939 * 2016$} & 12.01 & 13.04 & 11.96 & 12.89 & 9.977 & 11.07 \\
\hline & $(0.0951)$ & $(0.151)$ & $(0.0910)$ & $(0.189)$ & $(0.0748)$ & $(0.136)$ \\
\hline & 82195.25 & 230234.31 & 78186.54 & 198164.50 & 10762.81 & 32107.75 \\
\hline \multirow[t]{3}{*}{$1940-1949 * 1987$} & 11.22 & 11.00 & 10.36 & 9.970 & 7.797 & 7.702 \\
\hline & $(0.0596)$ & $(0.0590)$ & $(0.160)$ & $(0.156)$ & $(0.0970)$ & $(0.103)$ \\
\hline & 37303.88 & 29937.07 & 15785.59 & 10687.74 & 1216.64 & 1106.38 \\
\hline \multirow[t]{3}{*}{$1940-1949 * 1988$} & 11.29 & 11.07 & 10.39 & 9.975 & 7.959 & 7.877 \\
\hline & $(0.0639)$ & $(0.0593)$ & $(0.182)$ & $(0.180)$ & $(0.106)$ & $(0.105)$ \\
\hline & 40008.72 & 32107.75 & 16266.33 & 10741.31 & 1430.60 & 1317.97 \\
\hline $1940-1949 * 1994$ & 11.22 & 11.18 & 10.14 & 9.980 & 7.714 & 7.708 \\
\hline & $(0.0753)$ & $(0.0812)$ & $(0.226)$ & $(0.217)$ & $(0.105)$ & $(0.117)$ \\
\hline & 37303.88 & 35841.18 & 12668.23 & 10795.15 & 1119.74 & 1113.04 \\
\hline $1940-1949 * 1998$ & 11.51 & 11.52 & 10.96 & 10.82 & 8.674 & 8.730 \\
\hline & $(0.108)$ & $(0.108)$ & $(0.237)$ & $(0.215)$ & $(0.144)$ & $(0.132)$ \\
\hline & 49853.94 & 50354.98 & 28763.22 & 25005.54 & 2924.42 & 3092.86 \\
\hline $1940-1949 * 2004$ & 11.98 & 12.08 & 11.25 & 11.19 & 9.001 & 9.164 \\
\hline & $(0.0861)$ & $(0.115)$ & $(0.189)$ & $(0.155)$ & $(0.122)$ & $(0.132)$ \\
\hline & 79766.01 & 88155.08 & 38439.95 & 36201.39 & 4055.59 & 4773.58 \\
\hline $1940-1949 * 2009$ & 12.35 & 12.77 & 11.93 & 12.15 & 10.07 & 10.45 \\
\hline & $(0.0562)$ & $(0.133)$ & $(0.0801)$ & $(0.151)$ & $(0.0682)$ & $(0.125)$ \\
\hline & 115480.02 & 175756.15 & 75875.78 & 94547.04 & 94547.04 & 17272.18 \\
\hline $1940-1949 * 2013$ & 12.24 & 13.02 & 11.80 & 12.39 & 9.919 & 10.64 \\
\hline & $(0.0688)$ & $(0.159)$ & $(0.131)$ & $(0.214)$ & $(0.0636)$ & $(0.126)$ \\
\hline & 103450.94 & 225675.36 & 66626.17 & 120192.85 & 10156.33 & 20886.38 \\
\hline $1940-1949 * 2016$ & 12.34 & 13.19 & 11.99 & 12.66 & 10.27 & 11.05 \\
\hline & $(0.0575)$ & $(0.145)$ & $(0.104)$ & $(0.178)$ & $(0.0775)$ & $(0.139)$ \\
\hline & 114330.97 & 267494.10 & 80567.67 & 157448.36 & 14426.94 & 31471.97 \\
\hline $1950-1959 * 1987$ & 10.77 & 10.52 & 8.130 & 7.874 & 7.687 & 7.525 \\
\hline & $(0.100)$ & $(0.0928)$ & $(0.402)$ & $(0.365)$ & $(0.0656)$ & $(0.0618)$ \\
\hline & 23786.00 & 18524.56 & 1697.39 & 1314.02 & 1089.91 & 926.90 \\
\hline $1950-1959 * 1988$ & 10.91 & 10.66 & 8.126 & 7.886 & 7.758 & 7.603 \\
\hline & $(0.0995)$ & $(0.0908)$ & $(0.380)$ & $(0.330)$ & $(0.0630)$ & $(0.0720)$ \\
\hline & 27360.42 & 21308.31 & 1690.62 & 1329.89 & 1170.10 & 1002.09 \\
\hline $1950-1959 * 1994$ & 10.84 & 10.78 & 8.646 & 8.594 & 7.269 & 7.281 \\
\hline & $(0.0765)$ & $(0.0748)$ & $(0.304)$ & $(0.305)$ & $(0.105)$ & $(0.0977)$ \\
\hline & 25510.68 & 24025.06 & 2843.67 & 2699.58 & 717.55 & 726.21 \\
\hline $1950-1959 * 1998$ & 11.13 & 10.98 & 10.04 & 9.848 & 8.043 & 7.940 \\
\hline & $(0.0982)$ & $(0.0940)$ & $(0.223)$ & $(0.201)$ & $(0.0968)$ & $(0.0912)$ \\
\hline & 34093.18 & 29344.27 & 11462.69 & 9460.23 & 1555.96 & 1403.68 \\
\hline $1950-1959 * 2004$ & 11.75 & 11.54 & 10.91 & 10.49 & 8.816 & 8.692 \\
\hline & $(0.0698)$ & $(0.0696)$ & $(0.175)$ & $(0.162)$ & $(0.109)$ & $(0.109)$ \\
\hline & 63376.77 & 51372.21 & 27360.42 & 17977.07 & 3370.62 & 2977.54 \\
\hline $1950-1959 * 2009$ & 12.15 & 12.03 & 11.11 & 10.84 & 9.712 & 9.594 \\
\hline & $(0.0432)$ & $(0.0544)$ & $(0.140)$ & $(0.122)$ & $(0.0731)$ & $(0.104)$ \\
\hline & 94547.04 & 83855.70 & 33418.09 & 25510.68 & 8257.29 & 7338.22 \\
\hline $1950-1959 * 2013$ & 12.19 & 12.18 & 11.47 & 11.30 & 9.759 & 9.754 \\
\hline & $(0.0498)$ & $(0.0773)$ & $(0.111)$ & $(0.151)$ & $(0.0592)$ & $(0.0986)$ \\
\hline & 98405.58 & 97426.43 & 47899.13 & 40410.81 & 8654.65 & 8611.49 \\
\hline $1950-1959 * 2016$ & 12.16 & 12.34 & 11.58 & 11.60 & 9.906 & 10.06 \\
\hline & $(0.0710)$ & $(0.102)$ & $(0.133)$ & $(0.147)$ & $(0.0601)$ & $(0.104)$ \\
\hline
\end{tabular}




\begin{tabular}{|c|c|c|c|c|c|c|}
\hline & 95497.25 & 114330.97 & 53468.75 & 54548.89 & 10025.15 & 11694.25 \\
\hline \multirow[t]{3}{*}{$1960-1969 * 1987$} & 9.426 & 9.604 & 3.729 & 4.649 & 7.062 & 7.202 \\
\hline & $(0.226)$ & $(0.140)$ & $(0.567)$ & $(0.441)$ & $(0.207)$ & $(0.158)$ \\
\hline & 6203.40 & 7411.97 & 20.80 & 52.23 & 583.38 & 671.05 \\
\hline \multirow[t]{3}{*}{$1960-1969 * 1988$} & 10.09 & 10.23 & 4.716 & 5.146 & 7.372 & 7.524 \\
\hline & $(0.120)$ & $(0.0551)$ & $(0.599)$ & $(0.529)$ & $(0.150)$ & $(0.105)$ \\
\hline & 12050.39 & 13861.25 & 55.85 & 85.86 & 795.40 & 925.97 \\
\hline \multirow[t]{3}{*}{$1960-1969 * 1994$} & 10.03 & 10.24 & 5.064 & 5.528 & 7.295 & 7.460 \\
\hline & $(0.108)$ & $(0.0936)$ & $(0.550)$ & $(0.541)$ & $(0.0953)$ & $(0.0906)$ \\
\hline & 11348.63 & 14000.56 & 79.10 & 125.81 & 736.45 & 868.57 \\
\hline \multirow[t]{3}{*}{$1960-1969 * 1998$} & 10.63 & 10.50 & 7.543 & 7.565 & 7.927 & 7.842 \\
\hline & $(0.110)$ & $(0.0808)$ & $(0.371)$ & $(0.344)$ & $(0.0932)$ & $(0.0756)$ \\
\hline & 20678.56 & 18157.75 & 943.74 & 964.73 & 1385.55 & 1272.64 \\
\hline \multirow[t]{3}{*}{$1960-1969 * 2004$} & 11.36 & 11.14 & 9.874 & 9.555 & 8.332 & 8.163 \\
\hline & $(0.118)$ & $(0.0594)$ & $(0.200)$ & $(0.113)$ & $(0.170)$ & $(0.137)$ \\
\hline & 42909.68 & 34435.82 & 9709.42 & 7057.54 & 2077.35 & 1754.34 \\
\hline \multirow[t]{3}{*}{$1960-1969 * 2009$} & 11.92 & 11.60 & 10.25 & 9.805 & 9.215 & 8.897 \\
\hline & $(0.0282)$ & $(0.0225)$ & $(0.117)$ & $(0.0858)$ & $(0.0439)$ & $(0.0385)$ \\
\hline & 75120.80 & 54548.89 & 14141.27 & 9062.06 & 5023.35 & 3655.00 \\
\hline \multirow[t]{3}{*}{$1960-1969 * 2013$} & 11.99 & 11.68 & 10.79 & 10.34 & 9.355 & 9.037 \\
\hline & $(0.0389)$ & $(0.0433)$ & $(0.120)$ & $(0.125)$ & $(0.0667)$ & $(0.0592)$ \\
\hline & 80567.67 & 59092.11 & 24266.51 & 15473.01 & 5778.23 & 4204.25 \\
\hline \multirow[t]{3}{*}{$1960-1969 * 2016$} & 12.03 & 11.79 & 10.85 & 10.49 & 9.432 & 9.186 \\
\hline & $(0.0634)$ & $(0.0572)$ & $(0.142)$ & $(0.117)$ & $(0.0764)$ & $(0.0701)$ \\
\hline & 83855.70 & 65963.23 & 25767.07 & 17977.07 & 6240.73 & 4879.76 \\
\hline \multirow[t]{3}{*}{$1970-1979 * 1994$} & 8.239 & 9.195 & 2.479 & 3.637 & 6.453 & 7.179 \\
\hline & $(0.462)$ & $(0.302)$ & $(0.563)$ & $(0.329)$ & $(0.215)$ & $(0.175)$ \\
\hline & 1892.87 & 4923.88 & 5.92 & 18.97 & 317.30 & 655.79 \\
\hline \multirow[t]{3}{*}{$1970-1979 * 1998$} & 9.090 & 9.542 & 4.181 & 5.009 & 7.151 & 7.427 \\
\hline & $(0.234)$ & $(0.139)$ & $(0.460)$ & $(0.439)$ & $(0.152)$ & $(0.126)$ \\
\hline & 4433.09 & 6966.39 & 32.70 & 74.87 & 637.68 & 840.37 \\
\hline \multirow[t]{3}{*}{$1970-1979 * 2004$} & 10.77 & 10.79 & 6.693 & 6.928 & 8.094 & 8.054 \\
\hline & $(0.187)$ & $(0.134)$ & $(0.487)$ & $(0.437)$ & $(0.0727)$ & $(0.0541)$ \\
\hline & 23786.00 & 24266.51 & 403.36 & 510.22 & 1637.38 & 1573.17 \\
\hline \multirow[t]{3}{*}{$1970-1979 * 2009$} & 11.60 & 11.31 & 8.667 & 8.358 & 8.875 & 8.557 \\
\hline & $(0.0746)$ & $(0.0580)$ & $(0.466)$ & $(0.414)$ & $(0.103)$ & $(0.0939)$ \\
\hline & 54548.89 & 40816.95 & 2904.02 & 2132.07 & 3575.47 & 2601.52 \\
\hline \multirow[t]{3}{*}{$1970-1979 * 2013$} & 11.84 & 11.53 & 9.828 & 9.474 & 8.965 & 8.612 \\
\hline & $(0.0612)$ & $(0.0549)$ & $(0.304)$ & $(0.277)$ & $(0.0639)$ & $(0.0607)$ \\
\hline & 69345.24 & 50861.05 & 9272.91 & 6508.4 & 3912.19 & 2748.61 \\
\hline \multirow[t]{3}{*}{$1970-1979 * 2016$} & 11.90 & 11.59 & 10.37 & 9.968 & 9.224 & 8.870 \\
\hline & $(0.0753)$ & $(0.0646)$ & $(0.232)$ & $(0.190)$ & $(0.0757)$ & $(0.0642)$ \\
\hline & 73633.31 & 54006.12 & 15944.23 & 10666.38 & 5068.76 & 3557.64 \\
\hline \multirow[t]{3}{*}{$1980-1989 * 2004$} & 8.563 & 9.478 & 3.171 & 4.112 & 7.201 & 7.820 \\
\hline & $(0.316)$ & $(0.211)$ & $(0.145)$ & $(0.623)$ & $(0.253)$ & $(0.217)$ \\
\hline & 2617.18 & 6534.51 & 11.89 & 30.52 & 670.38 & 1244.95 \\
\hline \multirow[t]{3}{*}{$1980-1989 * 2009$} & 10.03 & 10.42 & 4.552 & 5.128 & 8.006 & 8.208 \\
\hline & $(0.237)$ & $(0.158)$ & $(0.348)$ & $(0.298)$ & $(0.102)$ & $(0.0867)$ \\
\hline & 11348.63 & 16761.71 & 47.40 & 84.33 & 1499.44 & 1835.09 \\
\hline \multirow[t]{3}{*}{$1980-1989 * 2013$} & 10.75 & 10.85 & 5.870 & 6.222 & 8.463 & 8.442 \\
\hline & $(0.204)$ & $(0.146)$ & $(0.462)$ & $(0.410)$ & $(0.106)$ & $(0.0701)$ \\
\hline & 23315.01 & 25767.07 & 177.12 & 251.85 & 2368.12 & 2318.91 \\
\hline \multirow[t]{3}{*}{$1980-1989 * 2016$} & 11.04 & 11.08 & 7.659 & 7.991 & 8.543 & 8.481 \\
\hline & $(0.198)$ & $(0.141)$ & $(0.351)$ & $(0.253)$ & $(0.119)$ & $(0.0776)$ \\
\hline & 31158.82 & 32430.44 & 1059.81 & 1477.12 & 2565.35 & 2411.13 \\
\hline $\mathrm{N}$ & 48935 & 48935 & 48935 & 48935 & 48935 & 48935 \\
\hline
\end{tabular}

Standard errors in parentheses.
Note: All predicted values are statistically significant $(\mathrm{p}<0.001)$, which are not marked in the results table to make it easy to read.

Note 2: We removed cohort*age and cohort*period interactions, which contain zero values as certain combinations cannot exist due to APC correlation.

Note 3: We applied the inverse function, $\frac{1}{2}(\exp (\beta x)+\exp (-\beta x))$, to obtain a more intuitive interpretation below each predicted value, under standard errors. 